\title{
A PROSÓdiA DE PERGUNTAS E ASSERÇões: UM ESTUDO SITUADO DE ESPANHOL NO BRASIL
}

\author{
THE PROSODY OF QUESTIONS AND ASSERTIONS: \\ A SITUATED STUDY OF SPANISH IN BRAZIL
}

\author{
Sabrina Lima de Souza Cerqueira | Lattes | scerqueira@unb.br \\ Universidade de Brasilia
}

João Antônio Moraes | Lattes | jamoraes3@gmail.com Universidade Federal do Rio de Janeiro $\mid \mathrm{CNPq}$

\section{Albert Rilliard | Lattes | Albert.Rilliard@limsi.fr LIMSI, CNRS, Université Paris Saclay | Universidade Federal do Rio de Janeiro}

Resumo: Neste trabalho, descreve-se a entoação (F0 e duração) de perguntas totais e parciais e de suas asserções correspondentes em enunciados lidos em espanhol por quatro informantes: duas brasileiras, falantes de espanhol como L2, e duas espanholas, falantes de espanhol como L1. Para a descrição e análise dos dados, partimos de trabalhos realizados para o português brasileiro (MORAES, 1998; CUNHA, 2000; MORAES, 2006, 2008; BARBOSA, 2012; FROTA, 2013) e para o espanhol (NAVARRO TOMÁS, 1944; SOSA, 1999; CANTERO, 2002; HIDALGO NAVARRO, 2006; ESTEBAS VILAPLANA, PRIETO, 2009; FERREIRA DE SÁ, 2013; SILVA, 2016). Os resultados mostram que o padrão mais frequente para enunciados do tipo pergunta total apresenta movimento ascendente na região prenuclear e na região nuclear. Nas perguntas parciais o movimento melódico predominante é descendente. As asserções se caracterizam por contorno prenuclear ascendente com pico geralmente na sílaba tônica ou postônica prenuclear, queda da F0 ao longo do enunciado e acento nuclear num nível médio ou baixo seguido de $\mathrm{FO}_{\text {final }}$ baixa. No que diz respeito ao parâmetro duração, em enunciados do tipo pergunta total e pergunta parcial, as 4 informantes apresentam padrão semelhante: encurtam as sílabas da região prenuclear e a pretônica nuclear e alongam a tônica e a postônica nucleares. Nos enunciados assertivos, observa-se que as informantes brasileiras encurtam as pretônicas e postônicas prenucleares e alongam as tônicas. As informantes espanholas, por sua vez, alongam pretônicas e tônicas prenucleares e encurtam as postônicas. Na região nuclear as 4 informantes apresentam padrão similar, com alongamento das tônicas e postônicas.

Palavras-chave: Prosódia; Pergunta; Asserção; L2. 
Abstract: This work describes the intonation of yes-no questions and Wh-questions and their corresponding assertions. The corpus is based on Spanish utterances read in Spanish by four speakers: two L2 Spanish speakers from Brazil and two L1 Spanish speakers from Spain. The work is based on preceding descriptions from Navarro Tomás, 1944; Moraes 1998; Sosa, 1999; Cunha, 2000; Cantero, 2002; Moraes J., 2006; Hidalgo Navarro, 2006; Moraes, 2008; Estebas Vilaplana \& Prieto, 2009; Barbosa, 2012; Frota, 2013; Ferreira de Sá, 2013; Silva, 2016. The results show that the most frequent pattern for yes-no questions has rising movement on the prenuclear region and on the nuclear region. For Wh-questions, the predominant melodic movement is falling. The assertions are characterized by a rising prenuclear contour with a peak generally on the pre-nuclear tonic or post-tonic syllable, followed by an F0 fall along the utterance and a nuclear stress at a medium or low level followed by a low F0. Regarding the duration criterion, in yesno and Wh-questions, the four informants present similar strategies: they shorten the prenuclear region as well as the nuclear pre-tonic syllables and lengthen nuclear tonic and post-tonic syllables. For the assertions statements, it is observed that the Brazilian informants shorten the prenuclear pre-tonic and post-tonic syllables and lengthen the tonic ones. The Spanish informants, in turn, lengthen pre-nuclear pre-tonic and tonic syllables and shorten post-tonic ones. For the nuclear region, the four informants present similar strategies, thus lengthening tonic and post-tonic syllables.

Keywords: Prosody; Questions; Assertions; L2.

\section{INTRODUÇÃO}

Quando se fala uma língua estrangeira, deve-se assegurar que os padrões entoacionais adotados ou que se tem como parâmetro correspondem aos do interlocutor, de maneira que a comunicação possa ser efetiva e eficiente. Segundo Quilis (1993), a entoação é o veículo ideal para transmitir as mais diversas informações como o tipo de enunciado (pergunta, asserção, pedido, entre outros), a origem do falante, seu estado emocional, o estrato social ao qual pertence, entre outras informações.

O objetivo deste trabalho é (i) descrever os padrões melódicos de enunciados interrogativos e assertivos produzidos na modalidade lida por quatro informantes: duas brasileiras, cariocas - falantes de espanhol como L2 - e duas espanholas, pamplonesas - falantes de espanhol como L1.

Nossa hipótese é que as informantes, independente da sua origem, ou seja, se são falantes de espanhol como L1 ou L2, realizarão padrões melódicos em perguntas e asserções convergindo com o esperado para a língua espanhola, pois se trata de um corpus lido, no qual há um maior controle na produção dos dados. 


\subsection{Os padrões entoacionais das perguntas em Espanhol e no PB $^{1}$}

Vários estudos versam sobre os padrões entoacionais de perguntas em português (MORAES, 1998; MIRA MATEUS, 2003; MORAES, 2006, 2008; BARBOSA, 2012; CUNHA, 2000; FROTA, 2013, entre outros) e em espanhol (NAVARRO TOMÁS, 1944; SOSA, 1999; CANTERO, 2002; HIDALGO NAVARRO, 2006; ESTEBAS VILAPLANA, PRIETO, 2009; FERREIRA DE SÁ, 2013; SILVA, 2016).

O primeiro a descrever o contorno melódico de perguntas para o espanhol foi Navarro Tomás (1944). Para as questões totais, o autor afirma, assim como Quilis (1993), que o contorno melódico em posição nuclear é sempre ascendente. As questões parciais ou pronominais, segundo o referido autor, apresentam os contornos representados na Figura 1, e ele os relaciona com valores pragmáticos da seguinte maneira: (1) contorno descendente é a forma não marcada; (2) padrão com terminação ascendente expressa insegurança ou suavidade, cortesia; (3) padrão circunflexo indica surpresa ou ênfase. Quilis (1993), por sua vez, afirma que as questões parciais apresentam um elemento gramatical, o pronome interrogativo, que identifica o enunciado como sendo interrogativo. Devido a isto, o contorno melódico é descendente, semelhante, portanto, aos enunciados declarativos. Um final ascendente em enunciados do tipo pergunta parcial para o autor indica maior polidez por parte do falante.

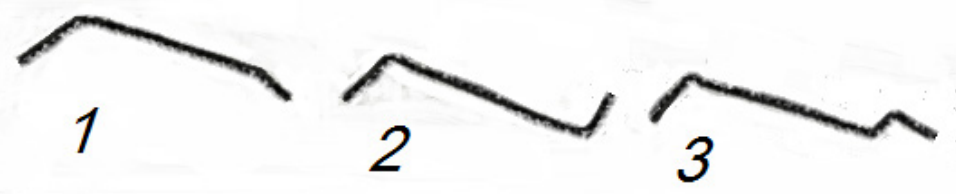

Figura 1: Configurações das perguntas pronominais segundo Navarro Tomás (1944).

Segundo Sosa (1999), o que vai diferenciar um enunciado interrogativo total de um declarativo em espanhol é a altura do início da frase interrogativa ${ }^{2}$ e os tonemas finais.

Segundo este autor, as perguntas parciais (ou pronominais, como chama o autor) sofrem um processo chamado upstep que faz com que tenhamos um tom de juntura ini-

\footnotetext{
${ }^{1}$ Nas seções 1.1 e 1.2 realiza-se revisão de trabalhos feitos anteriormente, sendo assim, optou-se, ao mencionar as descrições e os resultados apresentados nos mesmos, por manter a nomenclatura técnica utilizada em cada trabalho.

2 "En español la altura tonal de um enunciado interrogativo es desde su inicio siempre más alta que para la afirmación correspondiente y es esta frecuencia fundamental incrementada uno de los indicadores de que se trata en efecto de una pregunta y no de una afirmación. Así, por ejemplo, en el caso de las interrogaciones absolutas que, como vimos, no tienen una forma sintáctica particular que las diferencien de las afirmaciones, esta mayor altura general del principio del enunciado integra, junto con los tonemas finales, los elementos pertinentes para que se interprete como pregunta y no como afirmación”. (SOSA, 1999, p. 150).
} 
cial alto (H\%), que eleva a um nível mais alto a primeira sílaba acentuada - se a compararmos com o nível neutro de enunciação. Para este autor, as perguntas parciais em espanhol apresentam, geralmente, uma inflexão inicial com um movimento ascendente e o corpo com movimento descendente. No entanto, o movimento pode apresentar picos gradativamente descendentes. A inflexão final tem um movimento descendente nas interrogativas parciais não marcadas. Em algumas variedades, como a mexicana e colombiana, pode ter inflexão final ascendente; não obstante, não é possível afirmar que o padrão com inflexão final ascendente seja neutro (SOSA, 2003, p. 238). Nas perguntas totais, a inflexão final é predominantemente ascendente $\left(\mathrm{H}^{*} \mathrm{H} \%, \mathrm{~L}^{*} \mathrm{H} \%, \mathrm{~L}^{*}+\mathrm{HH} \%\right.$ (SOSA, 1999; p. 149), ainda que não se limite a este padrão.

Sosa (1999) menciona o contorno melódico circunflexo apenas para o padrão melódico das perguntas totais das cidades da região caribenha. Todas as demais cidades, independentes de estarem situadas na Espanha ou nas Américas, apresentam padrão nuclear ascendente, ainda que com ligeiras diferenças em sua representação por meio o SP$\mathrm{ToBi}^{3}$.

Em conformidade com o descrito por Navarro Tomás (1944), Quilis (1993) e Sosa (1999) estão os padrões descritos por Prieto para Madri, no Atlas Interactivo de la Entonación del Español ${ }^{4}$, a saber, ascendente para as interrogativas totais do tipo neutra ( $\left.\mathrm{L}^{*} \mathrm{HH} \%\right)$. Para as interrogativas parciais o padrão, segundo descrito no Atlas Interactivo de la Entonación del Español, é descendente para perguntas neutras $\left(\mathrm{H}^{*} \mathrm{~L}^{*} \mathrm{~L} \%\right)$.

Em trabalhos recentes realizados no Brasil comparando os padrões melódicos do espanhol e do PB, temos o seguinte panorama: Santos (2012) concluiu que o padrão circunflexo na região prenuclear e nuclear são as marcas prosódicas do espanhol uruguaio em perguntas totais. Para as perguntas parciais, a pesquisadora encontrou diferenças na região prenuclear nas duas regiões pesquisadas: descendente em Montevidéu e ascendente em Rivera (cidade fronteiriça com o Brasil). Para o português de Santana do Livramento e Porto Alegre, Santos (2012) descreve um padrão descendente na região prenuclear e nuclear.

Pinto (2009) encontrou grande influência do PB na produção do espanhol como língua estrangeira dos seus informantes. No Espanhol como Língua Materna (ELM), o padrão encontrado para as interrogativas totais é ascendente na região prenuclear e nuclear. Ao passo que em Português Língua materna (PLM) e Espanhol Língua Estrangeira (ELE) o contorno é $\mathrm{L}+\mathrm{H}^{*}$ no pretonema e $\mathrm{L}+\mathrm{H}^{*} \mathrm{~L} \%$ no tonema, ou seja, padrão circunflexo na região nuclear do enunciado.

\footnotetext{
${ }^{3} \mathrm{O}$ esquema de rotulagem Spanish ToBi, ou Sp-ToBi é uma ferramenta para anotação prosódica de corpus de fala em espanhol. Referido padrão de anotação contém informações prosódicas, fonéticas e entoacionais. Para mais informações, acessar: http://prosodia.upf.edu/atlasentonacion/tobi/index.html

${ }^{4} \mathrm{http}: / /$ prosodia.upf.edu/atlasentonacion/
} 
Dias (2015), por sua vez, em trabalho sobre declarativas e interrogativas totais no espanhol L1 e L2 falado em Bogotá, afirma que na região prenuclear, o contorno melódico de interrogativas totais produzidas por brasileiros (L2) começa com nível médio e as sílabas pretônicas raramente são identificadas como região de proeminência melódica. $\mathrm{Na}$ região nuclear, as tônicas são marcadas predominantemente com tons baixos. Nas sílabas postônicas finais do núcleo, prevalecem tons altos. No espanhol falado por colombianos (L1) a autora encontrou F0 alta na região prenuclear e no núcleo F0 com tons altos, ao contrário do observado em L2.

Gomes da Silva (2014) descreve um comportamento majoritariamente ascendente do ponto de vista fonético para as duas variedades estudadas em enunciados do tipo pergunta total, tendo sido encontrados também outros dois padrões de F0: circunflexo, descendente.

Para o PB, segundo Moraes (2008) temos, para a região nuclear: (i) uma subida melódica simples, limitada à última sílaba acentuada do enunciado, ou seja, um final circunflexo nas interrogativas totais; (ii) um movimento inicial ascendente e uma inflexão final descendente nas interrogativas parciais;

Rosignoli (2017) em estudo recente, propôs o seguinte quadro resumo dos padrões entoacionais de enunciados interrogativos descritos para o PB do Sudeste por Moraes (2008), Truckenbrodt, Sandalo e Abaurre (2009), Frota et al. (2015) e Castelo (2016):

Resumo dos contornos entoacionais das sentenças interrogativas das
variedades do

\begin{tabular}{|c|c|c|c|c|}
\hline $\begin{array}{r}\text { Autor (a) } \\
\text { (s) }\end{array}$ & Moraes (2008) & $\begin{array}{c}\text { Truckenbrodt, } \\
\text { Sandalo e } \\
\text { Abaurre } \\
\text { (2009) }\end{array}$ & $\begin{array}{c}\text { Frota et al. } \\
(2015 a)\end{array}$ & Castelo (2016) \\
\hline Tipo Frásico & Variedade carioca & $\begin{array}{c}\text { Variedade } \\
\text { paulista }\end{array}$ & $\begin{array}{c}\text { Variedade } \\
\text { paulista }\end{array}$ & $\begin{array}{c}\text { Variedade sulista } \\
\text { (RJ e MG) }\end{array}$ \\
\hline Global (sim/não) & $\begin{array}{c}\left(/ \mathrm{L}+\mathrm{H}^{*} /\right) / \mathrm{L}+<\mathrm{H}^{*} \\
\mathrm{~L} \% /\end{array}$ & $/ L^{*}+H \quad L \% /$ & $/ \mathrm{L}+\mathrm{H}^{*} \mathrm{~L} \% /$ & $\begin{array}{c}\left(/ L^{*}+\mathrm{H} /\right) / \mathrm{L}^{*}+\mathrm{H} \\
\mathrm{L} \% /\end{array}$ \\
\hline Confirmatória & /¡H+L*> L\%/ & - & - & - \\
\hline Retórica & $\begin{array}{c}\left(/ \mathrm{H}+\mathrm{H}^{*} /\right) \\
/ \mathrm{L}+>\mathrm{H}^{*} \mathrm{~L} \% /\end{array}$ & - & - & - \\
\hline Incredulidade & $/ \mathrm{H}+[\mathrm{LH}]^{*} \mathrm{~L} \% /$ & $/ L^{*}+\mathrm{H} L \% /$ & - & - \\
\hline Eco & - & - & /L*+H H\%l & - \\
\hline Parcial (QU-) & $\left(/ \mathrm{H}+\mathrm{H}^{*} /\right) / \mathrm{H}+\mathrm{L}^{*} \mathrm{~L} \% /$ & - & $/ \mathrm{H}+\mathrm{L}^{*} \mathrm{~L} \% /$ & - \\
\hline
\end{tabular}

Quadro 1: padrões entoacionais do Sudeste do PB (Rosignoli, 2017 p. 31) 
Ou seja, o padrão descrito para as diversas variedades do PB do Sudeste para as perguntas totais, apesar de apresentarem algumas diferenças, é o padrão circunflexo na região nuclear. Nas perguntas parciais, o padrão descrito por Moraes (2008) e Frota et al. (2015) para o Rio de Janeiro e São Paulo é descendente.

A carta do Atlas Linguístico do Brasil (AliB) (CARDOSO et al., 2015) sobre o padrão entoacional para perguntas totais descreve como padrão predominante aquele que tem acento nuclear ascendente-descendente. Observa-se com menos frequência padrão ascendente na tônica e postônica nucleares e padrão ascendente na postônica nuclear.

A partir das descrições e estudos realizados, podemos concluir que o padrão melódico mais produtivo nas perguntas totais do PB é aquele que apresenta comportamento de F0 ascendente-descendente na região nuclear. Para as perguntas parciais, a F0 é descendente na região nuclear.

\subsection{Padrões entoacionais das asserções em PB e Espanhol}

Segundo Navarro Tomás (1944), no espanhol, em asserções, o tom é uniforme, relativamente mais baixo do que nas questões. Quilis (1993), por sua vez, diz que enunciados declarativos apresentam curva melódica descendente na região nuclear. Prieto e Roseano (2009-2013) afirmam que as asserções neutras apresentam padrão prenuclear ascendente, cujo pico está deslocado para a sílaba postônica prenuclear - $\mathrm{L}+>\mathrm{H}^{*}-\mathrm{e}$ na região nuclear a curva de F0 é descendente até o final do enunciado, com tom de fronteira baixo $-\mathrm{L}^{*} \mathrm{~L} \%$.

Sosa (1999) afirma que os enunciados declarativos típicos da região de Pamplona, região das duas informantes deste trabalho, se caracterizam por um acento prenuclear $\mathrm{L}^{*}+\mathrm{H}$, característico da língua espanhola; na região nuclear, acento baixo $\mathrm{L}^{*} \mathrm{~L} \%$. Do ponto de vista linguístico e funcional, Sosa (1999, p. 195) afirma que não há diferenças significativas para as declarativas entre América e Espanha: região prenuclear com acento $\mathrm{L}^{*}+\mathrm{H}$ (com exceção do dialeto portenho) e na região nuclear acento $\mathrm{L}^{*} \mathrm{~L} \%$ e $\mathrm{H}^{*} \mathrm{~L} \%$, que marca maior ênfase ou focalização na última palavra acentuada.

Ballesteros (2014) descreve, utilizando corpus espontâneo extraído de programas televisivos, quatro características melódicas da entoação de Navarra: inflexões internas descendente, inflexões finais expressivas que ocorrem tanto com F0 ascendente (56\% dos dados) como descendente (44\% dos dados), deslocamento de picos (principalmente do primeiro pico do enunciado - $76 \%$ dos dados - e do pico final quando o contorno melódico é ascendente) e entoação circunflexa. 
Segundo Oliveira (2013), a entoação neutra das asserções em espanhol falado por brasileiros pode apresentar os seguintes contornos de F0 na região nuclear: plana; inflexão final descendente; circunflexa - ascendente-descendente e; circunflexa - descendente-ascendente.

Em português, Moraes e Rilliard (2014) destacam que os enunciados declarativos sofrem uma queda da F0 na posição nuclear final entre as sílabas pretônica e tônica. A Figura 2 ilustra os enunciados de 6 sílabas Roberta vai dançar e Roberta dançava, respectivamente. $\mathrm{O}$ tracejado mais claro indica sílaba tônica.

$60 x$

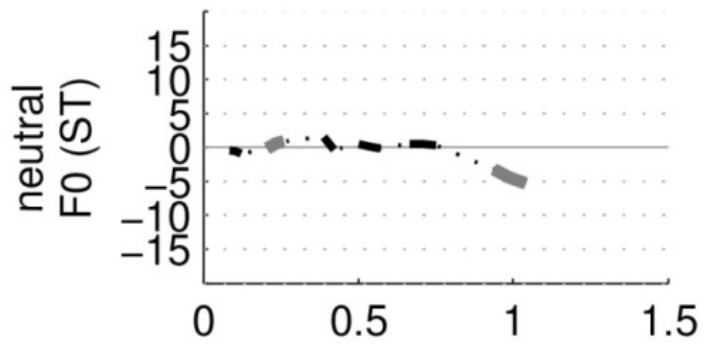

$6 p$

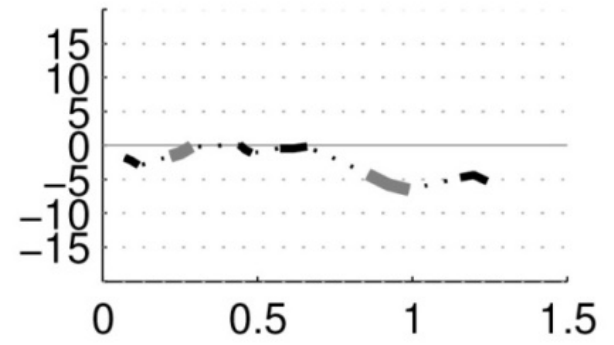

Figura 2: Padrão melódico de asserção no PB (Moraes \& Rilliard, 2014)

Moraes (2008) afirma que assertivas neutras apresentam uma subida melódica inicial (região prenuclear) cujo pico encontra-se na sílaba tônica ou postônica prenuclear (representado foneticamente por $\left[1+\mathrm{m}^{*}+\mathrm{h}\right]$ e fonologicamente por $\left.\mathrm{L}+\mathrm{H}^{*}\right)$. Para a região nuclear, o autor descreve F0 em nível médio para a sílaba pretônica e em nível baixo para a tônica, com configuração descendente (representado por $\mathrm{H}+\mathrm{L}^{*} \mathrm{~L} \%$ ).

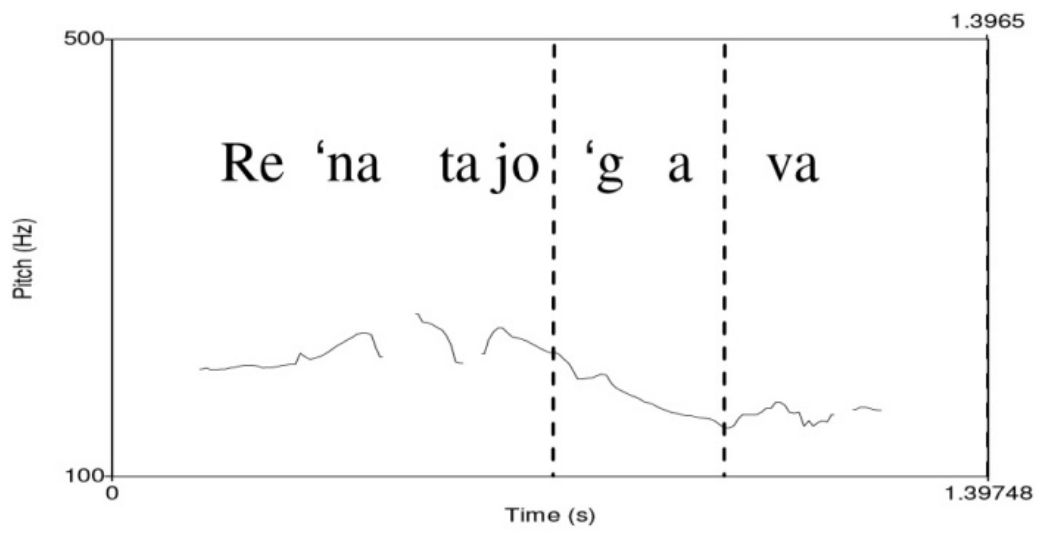

Figura 3: contorno melódico da assertiva neutra (Moraes, 2008) 
Silvestre (2012, p. 104) afirma que a homogeneidade impera entre as possibilidades de realização da asserção neutra nas capitais do país. Segundo a autora, há um tom $\mathrm{H}^{*}$ associado à primeira tônica do sintagma entoacional em asserções neutras.

Nas capitais do centro-oeste, sudeste e sul do Brasil o referido tom $\mathrm{H}^{*}$ da primeira tônica (região prenuclear) não se apresenta nas sílabas átonas adjacentes e é menos proeminente do que o tom alto observado na região nuclear dessas capitais (SILVESTRE, 2012, p. 104).

Para a região nuclear, a autora adotou a notação $\mathrm{H}+\mathrm{L}^{*} \mathrm{~L} \%$ para asserções neutras de falantes das regiões Norte, Nordeste, Centro-Oeste, e Sudeste do Brasil, ou seja, padrão descendente.

Silvestre e Cunha (2013) afirmam, em estudo realizado para três capitais brasileiras (Natal, Rio de Janeiro e Porto Alegre) que na região prenuclear o contorno melódico assertivo é predominantemente ascendente. Já na região nuclear, as autoras supracitadas observaram padrão descendente paras as variedades de Natal e Rio de Janeiro. Para Porto Alegre foi observado padrão circunflexo.

\section{METODOLOGIA}

\subsection{Informantes}

Este trabalho recebeu a colaboração de 4 professoras de duas universidades, todas com idade entre 25 e 45 anos, sendo duas brasileiras, naturais da região Sudeste (todas cariocas) e duas espanholas (ambas de Pamplona, Navarra), todas falantes da variedade castelhana (MORENO FERNÁNDEZ, 2010; LIPSKI, 2014). Todas as informantes possuem pelo menos curso de graduação completo, sendo que três possuem mestrado e a quarta estava cursando o mestrado na época das gravações do corpus. Todas são professoras em universidades federais no Brasil em cursos de Letras, sendo duas professoras substitutas $^{5}$ e duas professoras assistentes ${ }^{6}$.

Na Tabela 1 apresentamos algumas informações sobre as informantes;

\footnotetext{
${ }^{5}$ Professora substituta é aquela que presta concurso público para ter um contrato temporário com a instituição de ensino.

${ }^{6}$ Professora assistente é aquela que prestou concurso público para ingressar como professora universitária efetiva da instituição de ensino e possui título de mestre.
} 
Tabela 1: Dados das informantes

\begin{tabular}{|c|c|c|c|c|}
\hline $\begin{array}{l}\text { Identificação da } \\
\text { informante }\end{array}$ & Su & $\mathbf{H}$ & $\mathbf{T}$ & $\mathbf{C}$ \\
\hline & \multicolumn{2}{|c|}{ ESPANHOLAS } & \multicolumn{2}{|c|}{ BRASILEIRAS } \\
\hline $\begin{array}{c}\text { Espanhol é sua } \\
\text { língua }\end{array}$ & Materna (L1) & Materna (L1) & Estrangeira (L2) & Estrangeira (L2) \\
\hline Sua idade é & de 36 a 45 anos & de 25 a 35 anos & de 25 a 35 anos & de 25 a 35 anos \\
\hline Cidade natal & $\begin{array}{c}\text { Pamplona, } \\
\text { Navarra } \\
\text { (Espanha) }\end{array}$ & $\begin{array}{c}\text { Pamplona, } \\
\text { Navarra } \\
\text { (Espanha) }\end{array}$ & $\begin{array}{c}\text { Rio de Janeiro } \\
\text { - RJ }\end{array}$ & Rio de Janeiro - RJ \\
\hline $\begin{array}{l}\text { Cidade onde } \\
\text { mora atualmen- } \\
\text { te }\end{array}$ & Brasília - DF & Brasília - DF & $\begin{array}{c}\text { Rio de Janeiro } \\
\text { - RJ }\end{array}$ & Rio de Janeiro - RJ \\
\hline Escolaridade & Mestrado & Mestrado & Graduação & Mestrado \\
\hline $\begin{array}{l}\text { Locais onde } \\
\text { estudou: }\end{array}$ & $\begin{array}{l}\text { Graduação na } \\
\text { Universidade } \\
\text { de Alicante } \\
\text { (Valência, } \\
\text { Espanha), mestra- } \\
\text { do na Universidad } \\
\text { Completense } \\
\text { de Madrid } \\
\text { (Espanha), } \\
\text { pós-graduação } \\
\text { na FLACSO de } \\
\text { Quito (Equador) }\end{array}$ & $\begin{array}{c}\text { Universitat } \\
\text { Autònoma } \\
\text { de Barcelona, } \\
\text { Universidad } \\
\text { Nacional de } \\
\text { Educación } \\
\text { a Distancia, } \\
\text { Universidade de } \\
\text { Brasília }\end{array}$ & UFRJ & $\begin{array}{l}\text { Graduação e mes- } \\
\text { trado na UFRJ }\end{array}$ \\
\hline $\begin{array}{l}\text { Lugares onde } \\
\text { morou antes de } \\
\text { chegar ao Brasil }\end{array}$ & $\begin{array}{c}\text { Sartaguda, } \\
\text { Alicante, Córdoba } \\
\text { e Madrid } \\
\text { (Espanha), } \\
\text { Sttutgart } \\
\text { (Alemanha), } \\
\text { Inglaterra, Lomé } \\
\text { (Togo), Pedro } \\
\text { Juan Caballero } \\
\text { (Paraguai), Quito } \\
\text { (Equador) }\end{array}$ & $\begin{array}{c}\text { Barcelona } \\
\text { (Espanha), } \\
\text { Londres } \\
\text { (Inglaterra). }\end{array}$ & $\begin{array}{l}\text { Sempre morou } \\
\text { no Brasil }\end{array}$ & $\begin{array}{c}\text { Sempre morou no } \\
\text { Brasil }\end{array}$ \\
\hline $\begin{array}{l}\text { Lugares onde } \\
\text { morou no Brasil }\end{array}$ & Brasília - DF & $\begin{array}{c}\text { Salvador - BA, } \\
\text { Rio de Janeiro } \\
\text { - RJ. }\end{array}$ & $\begin{array}{l}\text { São Paulo - SP } \\
\text { Rio de Janeiro } \\
\text { - RJ }\end{array}$ & Rio de Janeiro - RJ \\
\hline $\begin{array}{c}\text { Há quanto } \\
\text { tempo está no } \\
\text { Brasil? }\end{array}$ & 4 anos e 7 meses & 11 anos & 32 anos & 30 anos \\
\hline $\begin{array}{l}\text { Quais idiomas } \\
\text { você fala? }\end{array}$ & $\begin{array}{l}\text { A:Espanhol; } \\
\text { B: Inglês; } \\
\text { C: Português; } \\
\text { D: Francês; } \\
\text { E: Catalão; } \\
\text { F: Alemão }\end{array}$ & $\begin{array}{l}\text { A:Espanhol; } \\
\text { B: Português; } \\
\text { C: Inglês }\end{array}$ & $\begin{array}{l}\text { A: Português; } \\
\text { B: Espanhol; } \\
\text { C: Inglês }\end{array}$ & $\begin{array}{l}\text { A: Português; } \\
\text { B: Espanhol; } \\
\text { C: Inglês }\end{array}$ \\
\hline $\begin{array}{c}\text { Em que } \\
\text { situações } \\
\text { utiliza a língua } \\
\text { espanhola }\end{array}$ & $\begin{array}{l}\text { Para falar com a } \\
\text { família e trabalhar }\end{array}$ & $\begin{array}{l}\text { Para falar com a } \\
\text { família e traba- } \\
\text { lhar }\end{array}$ & Para trabalhar & $\begin{array}{l}\text { Para trabalhar e } \\
\text { falar com amigos }\end{array}$ \\
\hline
\end{tabular}




\subsection{Corpus}

Os dados que compõe este corpus são, em sua maioria, baseados em enunciados que ocorreram espontaneamente durante aulas gravadas ministradas pelas informantes. Posteriormente, os enunciados foram selecionados e foram feitas as gravações dos dados individualmente em laboratório.

No quadro abaixo se podem ver os 24 enunciados que foram lidos pelas quatro informantes, totalizando $96^{7}$ dados. Os enunciados foram controlados com relação a sua extensão: curtos (de 1 a 4 sílabas), médios (de 5 a 9 sílabas) e longos (mais de 10 sílabas), bem como em relação a sua pauta acentual, sendo metade deles terminados por vocábulos oxítonos, e metade por paroxítonos. Optou-se, sempre que possível, por ter um par mínimo entre pergunta e asserção.

Os enunciados são:

Tabela 2: Corpus

\begin{tabular}{|c|c|c|}
\hline & Interrogativos & Assertivos \\
\hline \multirow{6}{*}{$\underset{\text { "total" }}{\text { Enunciados do tipo }}$} & ¿Te contesté? & Te contesté. \\
\hline & ¿La hicisteis? & Lo saben. \\
\hline & ¿Se puede leer? & Lo consiguen leer. \\
\hline & ¿Esto está correcto? & Esto está correcto. \\
\hline & $\begin{array}{l}\text { ¿Han leído el texto teórico } \\
\text { del curso? }\end{array}$ & $\begin{array}{c}\text { Han leído el texto teórico del } \\
\text { curso. }\end{array}$ \\
\hline & ¿Esto es correcto en español? & $\begin{array}{l}\text { Esto está bastante bien en } \\
\text { español. }\end{array}$ \\
\hline \multirow{6}{*}{$\begin{array}{l}\text { Enunciado do tipo } \\
\text { "parcial" }\end{array}$} & ¿Cuándo? & Como Pedro. \\
\hline & ¿Por qué? & Como José. \\
\hline & ¿Qué pusieron? & Cuando pueda yo. \\
\hline & ¿Cuál es el error? & Cuando lo hizo Pedro. \\
\hline & $\begin{array}{c}\text { ¿Cómo justificarían la } \\
\text { respuesta? }\end{array}$ & $\begin{array}{c}\text { Cómo justificarían la respues- } \\
\text { ta. }\end{array}$ \\
\hline & $\begin{array}{l}\text { ¿Qué pasó con la gente de } \\
\text { traducción? }\end{array}$ & $\begin{array}{l}\text { Qué pasó con la gente de } \\
\text { traducción. }\end{array}$ \\
\hline
\end{tabular}

\subsection{Medidas realizadas}

Utilizamos o programa Praat (BOERSMA, WEENINK, 2009) para fazer a segmentação dos enunciados, a estimação da F0 e da duração, bem como para a geração de figuras.

\footnotetext{
${ }^{7}$ Neste artigo apresentamos os resultados obtidos com a descrição de 96 enunciados lidos, sendo 48 enunciados interrogativos ( 12 de cada informante) e 48 enunciados assertivos ( 12 de cada informante).
} 
Para a análise do comportamento da duração, medimos, utilizando o script SGdetector (BARBOSA, CAMARGO, MADUREIRA, 2016) que roda no Praat, a extensão de cada sílaba dos enunciados produzidos pelas informantes.

A partir dos valores brutos, em milissegundos ( $\mathrm{ms})$, calculamos escores- $\mathrm{z}$ das medidas de duração por informante, seguindo a equação seguinte, onde $\mathrm{x}$ é a medida de duração em milissegundo, $\mu$ é a média e $\sigma$ o desvio padrão das durações silábicas de um falante.

Para análise do comportamento da F0 usaremos, além do traçado da F0, medidas da distribuição dos valores de F0: os percentis 10, 50 (mediana) e 90 em semitons. Os valores de percentis 10 e 90 foram escolhidos como valores representativos de valores extremos, próximos do mínimo e do máximo do falante, mas sendo mais estáveis que o mínimo e máximo absoluto, sujeitos a erros de estimação de F0.

\section{RESULTADOS}

\subsection{Perguntas Totais}

\subsubsection{Informantes brasileiras}

\subsubsection{Frequência fundamental}

Enunciados do tipo perguntas totais produzidos pelas informantes brasileiras podem ser caracterizados globalmente por um movimento ascendente-descendente na região prenuclear. Na região nuclear dois contornos de F0 são produtivos: ascendente-descendente, que é o que padrão predominante ( 8 de 12 dados), e ascendente (4 de 12 dados).

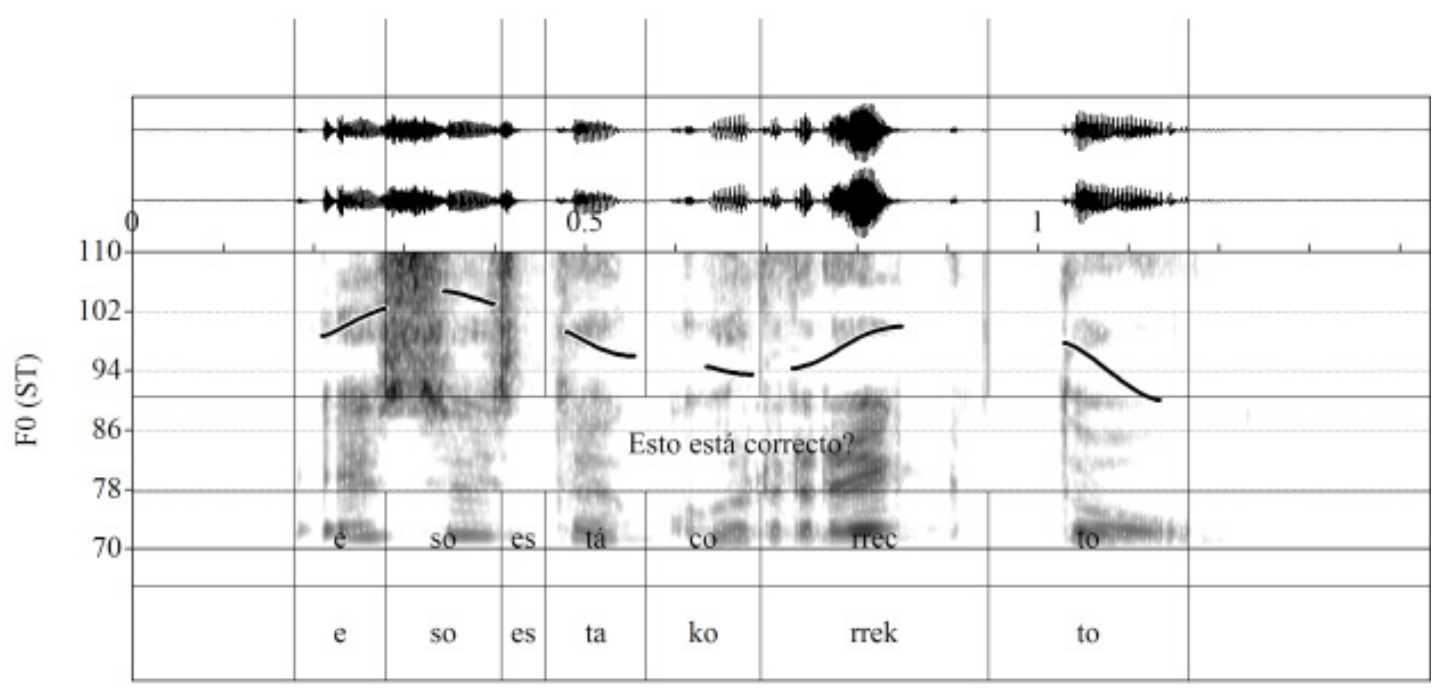

Figura 2: Pergunta total $¿$ Eso está correcto? - com padrão ascendente-descendente nas regiões prenuclear e nuclear, informante $\mathrm{C}$. 
Os dados com padrão ascendente-descendente na região nuclear (Figura 4) apresentam subida de F0 na sílaba pretônica ou tônica e a F0 cai no final da tônica ou na postônica nuclear.

Não parece haver relação entre o padrão da curva de F0 e a tonicidade do último vocábulo do enunciado, sendo antes sua realização variável relacionada ao falante. Observase, assim, que todos os enunciados produzidos com final ascendente da informante $\mathrm{C}$ terminam em vocábulo oxítono, enquanto que todos os enunciados ascendentes da informante $\mathrm{T}$ terminam em paroxítono, com exceção de um enunciado, que apresenta padrão circunflexo na região nuclear.

\subsubsection{Duração}

$\mathrm{Na}$ Figura 5, apresenta-se a média de duração das sílabas na região prenuclear em milissegundos (ms) e, na Figura 6, os valores normalizados de $z$-score. É possível afirmar, analisando os referidos valores, que as sílabas da região prenuclear proferidas pelas brasileiras estão propensas a sofrer encurtamento em relação à média global das sílabas de todos os enunciados ( $z$-score negativo), sendo que as postônicas prenucleares são as que mais se afastam da média, ou seja, são as mais breves.

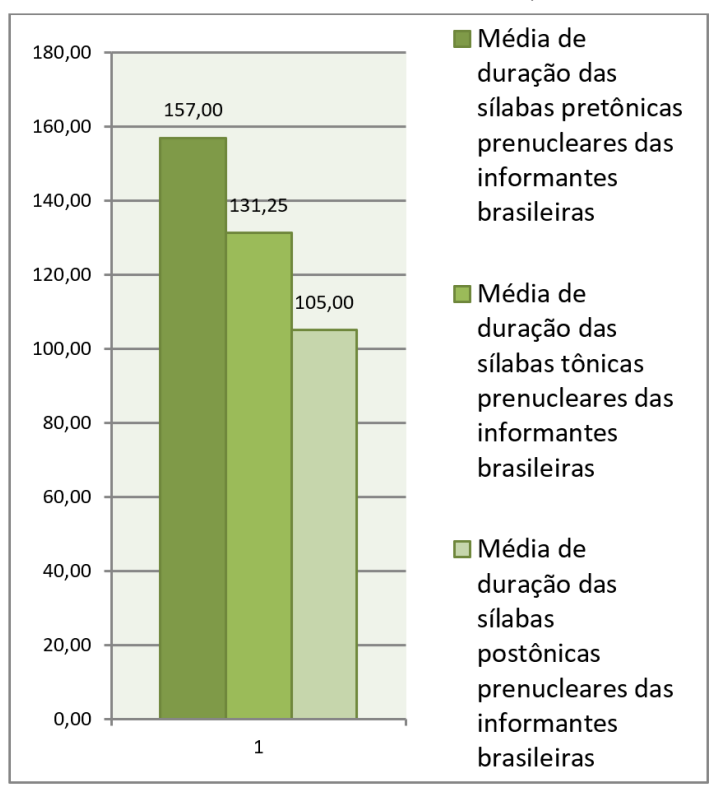

Figura 3: Duração média das sílabas (em Figura 4: Média do $z$-score para as sílabas ms) da região prenuclear das informantes da região prenuclear das informantes brasibrasileiras leiras

Para a região nuclear (Figuras 7 e 8), pode-se afirmar que a sílaba mais curta é a pretônica nuclear e a mais longa é a postônica nuclear. Tal fenômeno é descrito na litera- 
tura como alongamento final ou prepausal (FROTA, 2013; HIRST, DI CRISTO, 1998; ORTEGA-LLEBARIA, PRIETO, 2007).
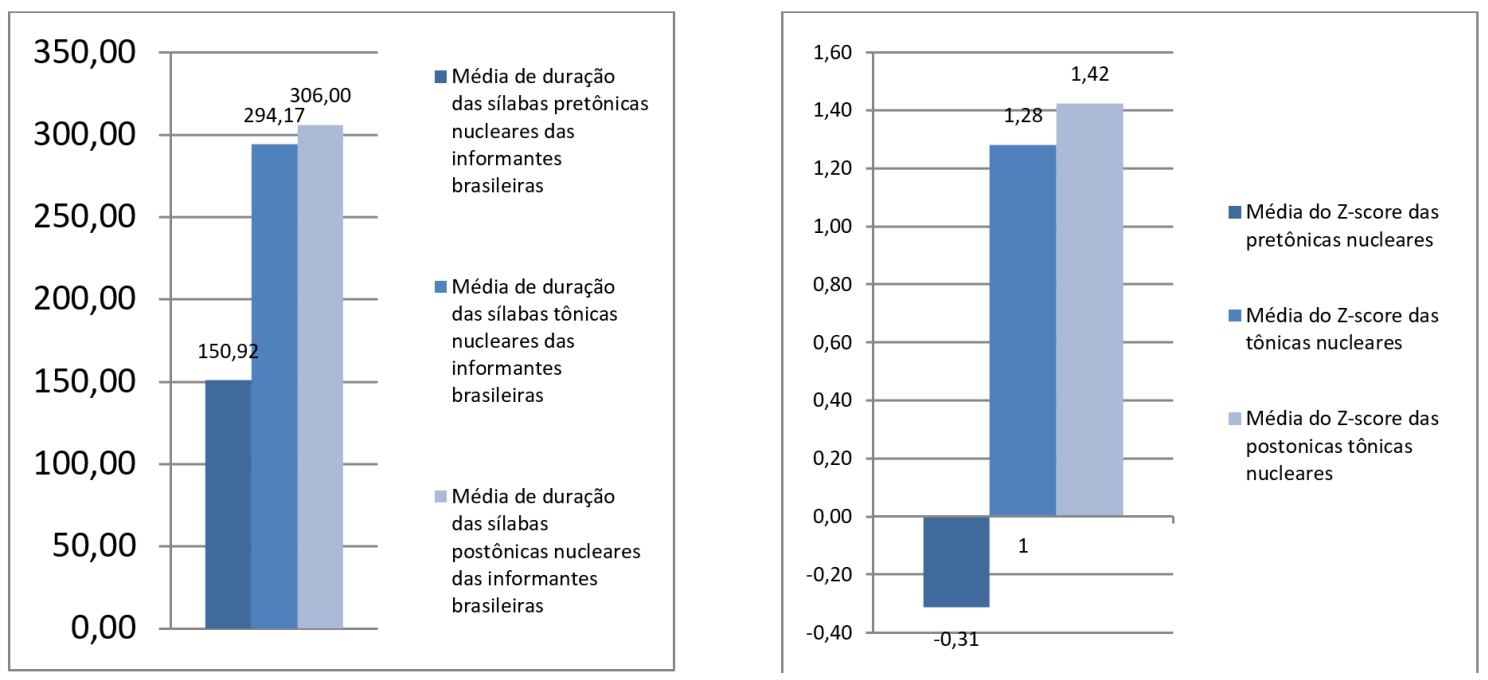

Figura 5: Média de duração das sílabas Figura 6: Média do $z$-score para as sílabas da (em ms) da região nuclear das informantes região nuclear das informantes brasileiras brasileiras

Os valores de $z$-score (Figura 8) apontam que na região nuclear há uma tendência em alongar as sílabas. No entanto, para a posição pretônica, nota-se propensão para o encurtamento da sílaba ou sua realização próxima da média global individual ( $z$-score negativo, com valor bem próximo de zero).

\subsubsection{Informantes espanholas}

\subsubsection{Frequência fundamental}

Os contornos melódicos das informantes espanholas se caracterizam por apresentar na região prenuclear F0 ascendente-descendente, com pico na postônica prenuclear. Na região nuclear, a curva de F0 sobe na sílaba tônica (contorno melódico ascendente - 5 de 12 dados) e desce quando existe uma postônica, configurando um padrão circunflexo (7 de 12 dados). Em enunciados terminados em vocábulos oxítonos, observa-se $\mathrm{F}_{\text {final }}$ alta, com exceção de um enunciado. 


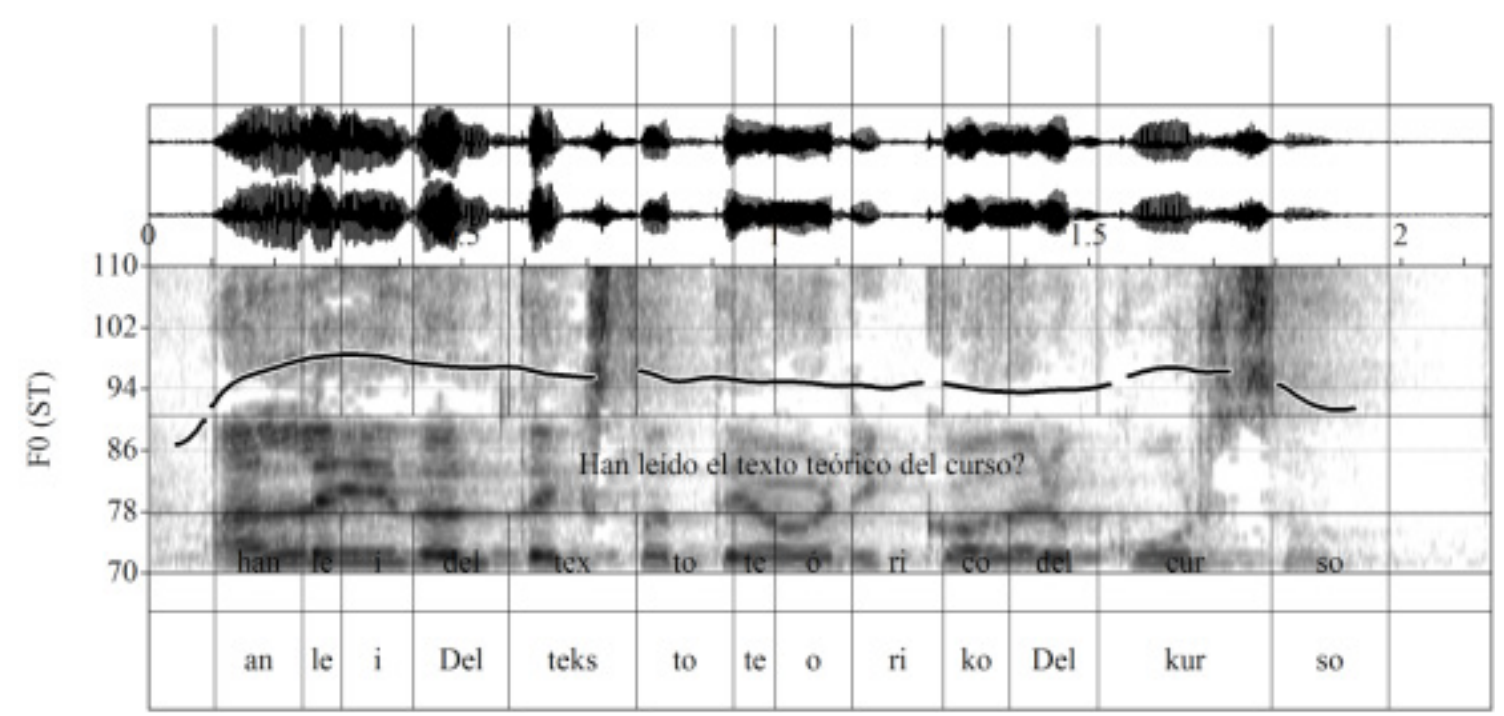

Figura 7: Pergunta total terminada em vocábulo paroxítono ${ }_{i}$ Han leído El texto teórico del curso? - com contorno de F0 ascendente-descente na região nuclear, informante $\mathrm{H}$.

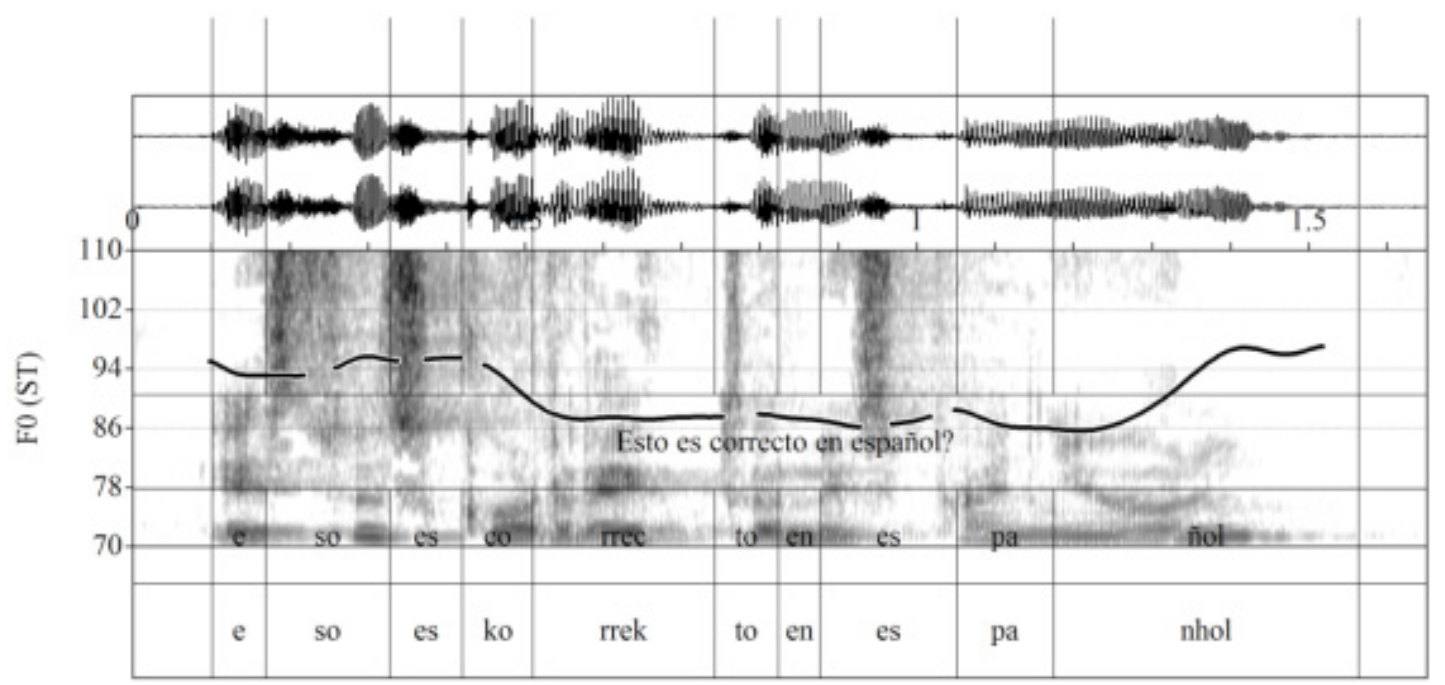

Figura 8: Pergunta total terminada com vocábulo oxítono ¿Esto es correcto en español? - com padrão ascendente na região nuclear, informante $T$.

\subsubsection{Duração}

O comportamento da duração representado nas Figuras 11 e 12 é de redução das sílabas da região prenuclear, uma vez que essas sílabas apresentam valores de $z$-score negativos, sendo as tônicas as sílabas mais encurtadas. 

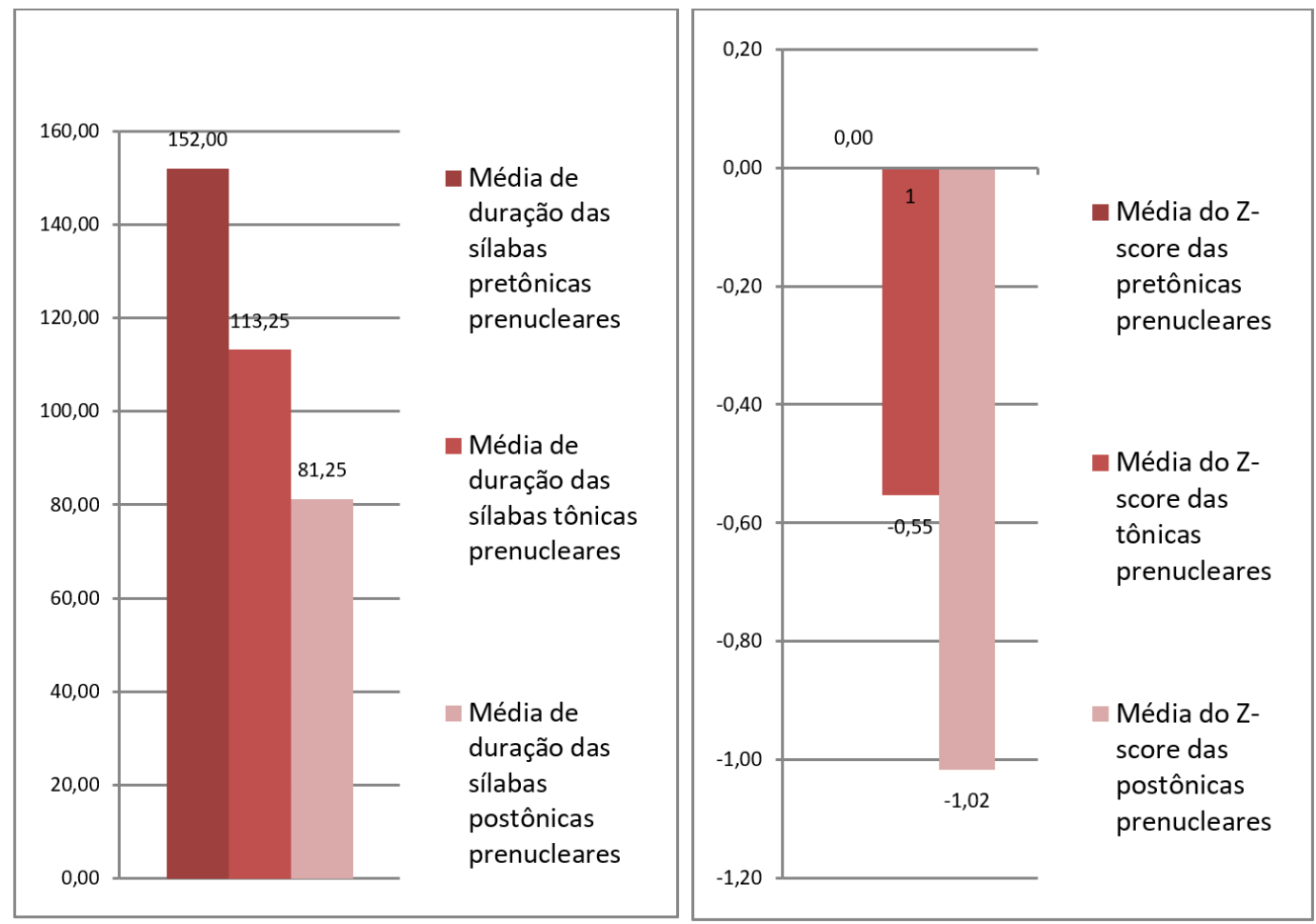

Figura 9: Duração média das sílabas (em ms) Figura 10: Média do $z$-score para as sílabas da da região prenuclear das informantes espa- região prenuclear das informantes espanholas nholas

O comportamento das sílabas na região nuclear está representado nas Figuras 13 e 14 .
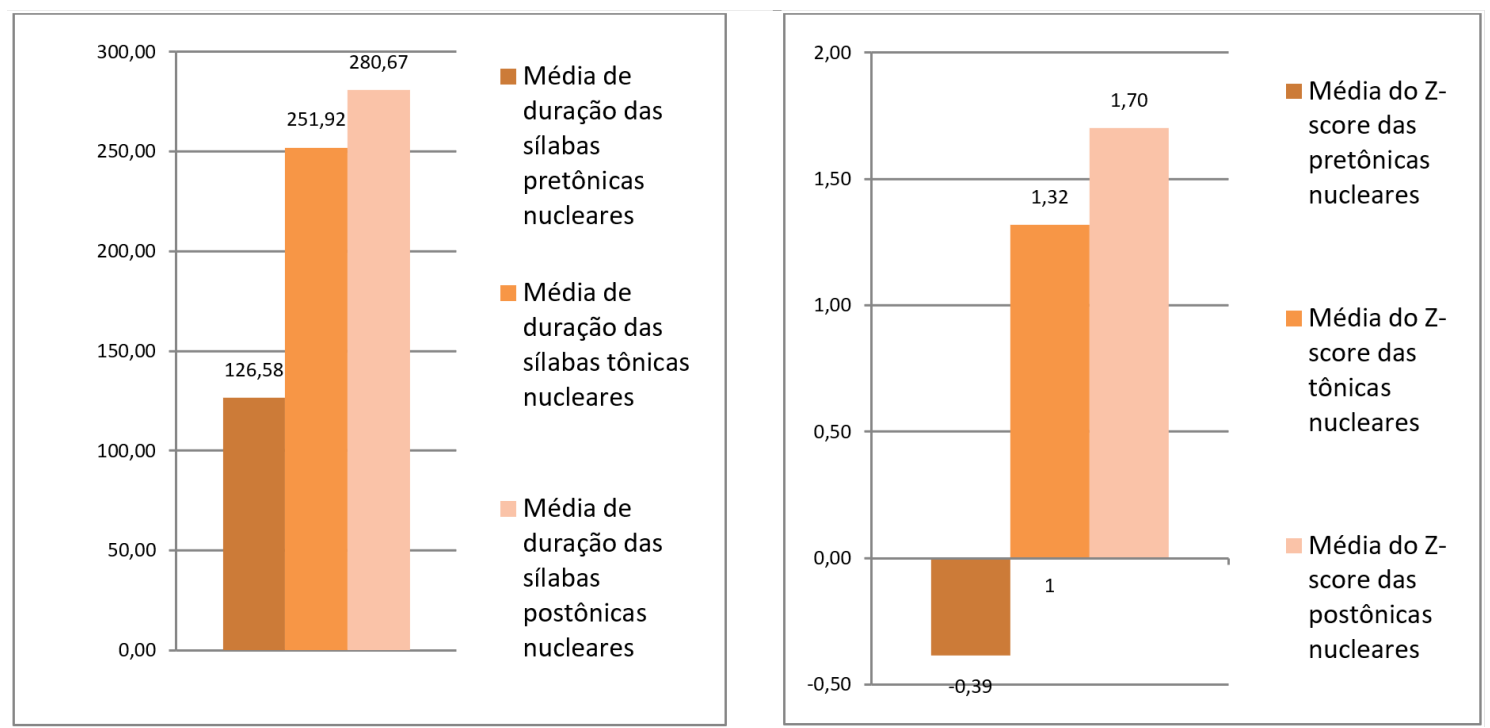

Figura 11: Duração média das sílabas (em ms) Figura 12: Média do $z$-score para as sílabas da região nuclear das informantes espanholas da região prenuclear das informantes espanholas 
Nota-se que as sílabas pretônicas são as mais curtas e apresentam $z$-score negativo, as sílabas tônicas e postônicas são mais longas do que a média. Assim como na região nuclear das informantes brasileiras, observa-se nos enunciados das informantes espanholas alongamento final das sílabas na região nuclear.

Por meio dos valores de $z$-score é possível afirmar que não encontramos diferenças expressivas na duração das sílabas das informantes brasileiras e espanholas; tanto um grupo quanto o outro tende a encurtar as sílabas pretônicas nucleares e alongar as sílabas tônicas e postônicas nucleares.

\subsection{Perguntas parciais}

\subsubsection{Informantes brasileiras}

\subsubsection{Frequência fundamental}

A entoação da interrogativa parcial das brasileiras se caracteriza por apresentar um padrão predominantemente descendente, sendo que, em alguns casos, observa-se na região prenuclear um movimento ascendente-descendente cujo pico encontra-se frequentemente na sílaba postônica prenuclear. Na região nuclear, predomina o padrão descendente ( 9 de 12 dados), porém, em alguns enunciados pode ocorrer um padrão circunflexo (3 de 12), com pico inferior ao primeiro pico da região prenuclear.

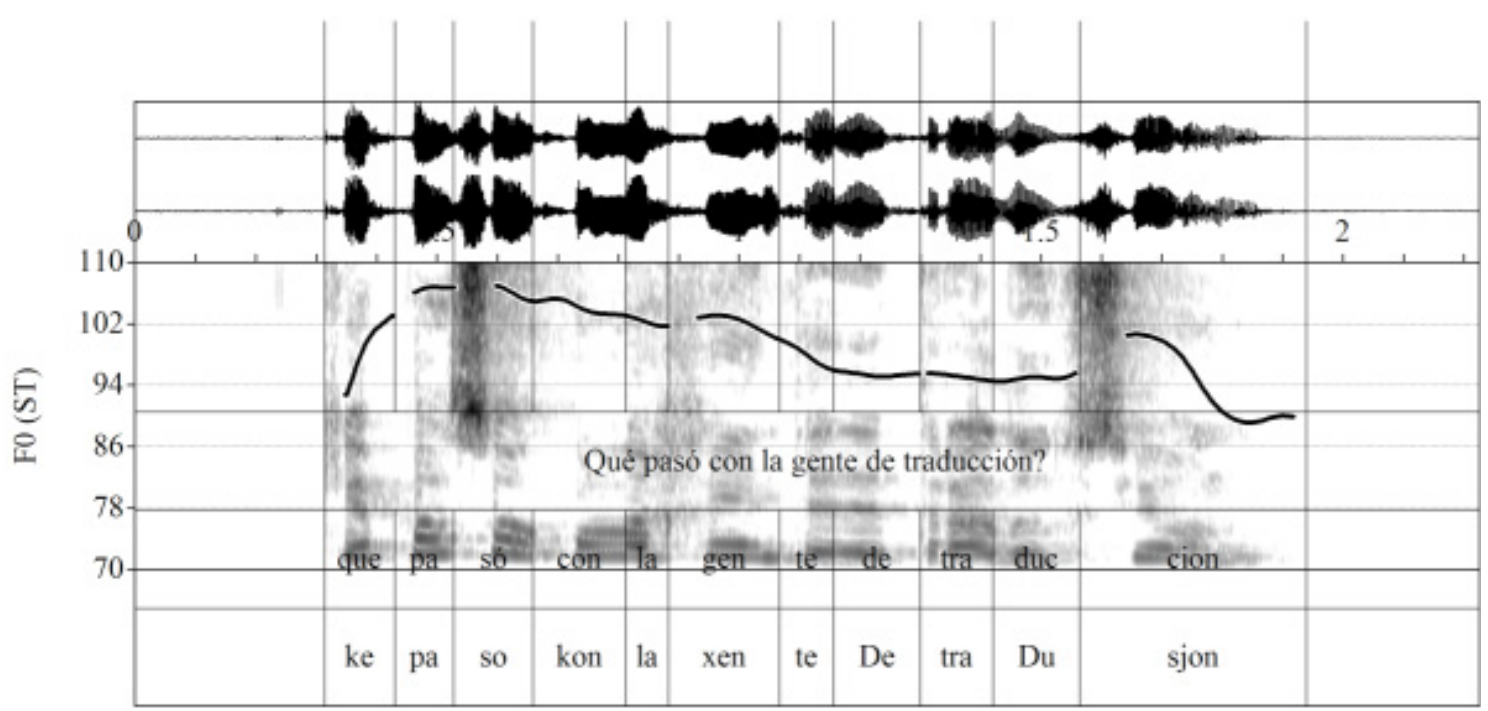

Figura 13: Pergunta parcial ¿Qué pasó com la gente de traducción? com padrão de F0 circunflexo na região nuclear, informante $\mathrm{T}$. 


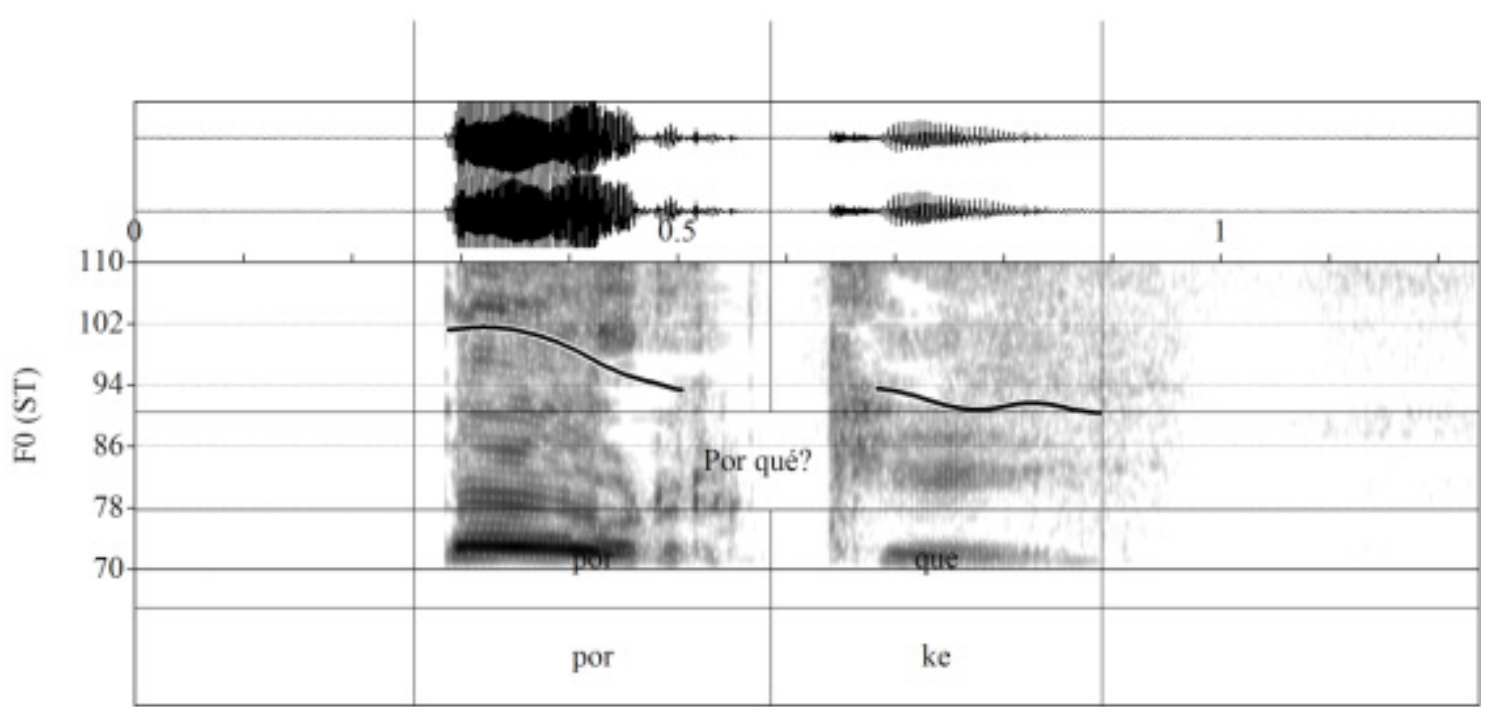

Figura 14: Pergunta parcial ¿Por qué? Com padrão descendente, informante C.

\subsubsection{Duração}

No que respeita à duração na região prenuclear, observa-se a tendência para o encurtamento das sílabas ( $z$-score negativos); as sílabas mais longas são as tônicas prenucleares e as postônicas as mais curtas (Figura 17).
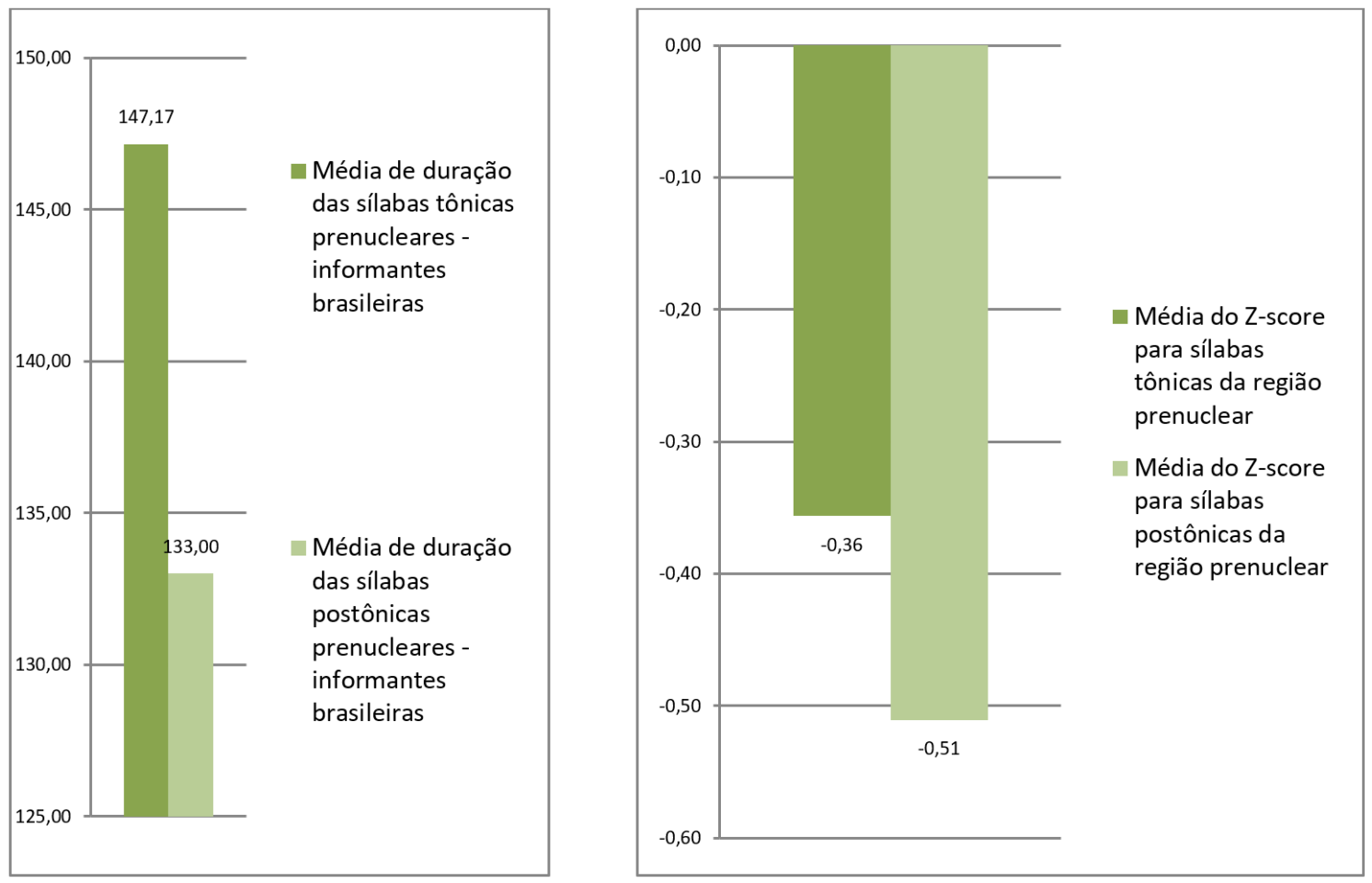

Figura 15: Média de duração das sílabas da Figura 16: Média do z-score para região região prenuclear - informantes brasileiras prenuclear - informantes brasileiras 
Para a região nuclear (Figuras 19 e 20), observa-se tendência para o alongamento da tônica (em consonância com as descrições para o português brasileiro), bem como da postônica nuclear, conforme esperado e descrito para o espanhol (GOMES DA SILVA, 2014, PINTO, 2009; SANTOS, 2012).
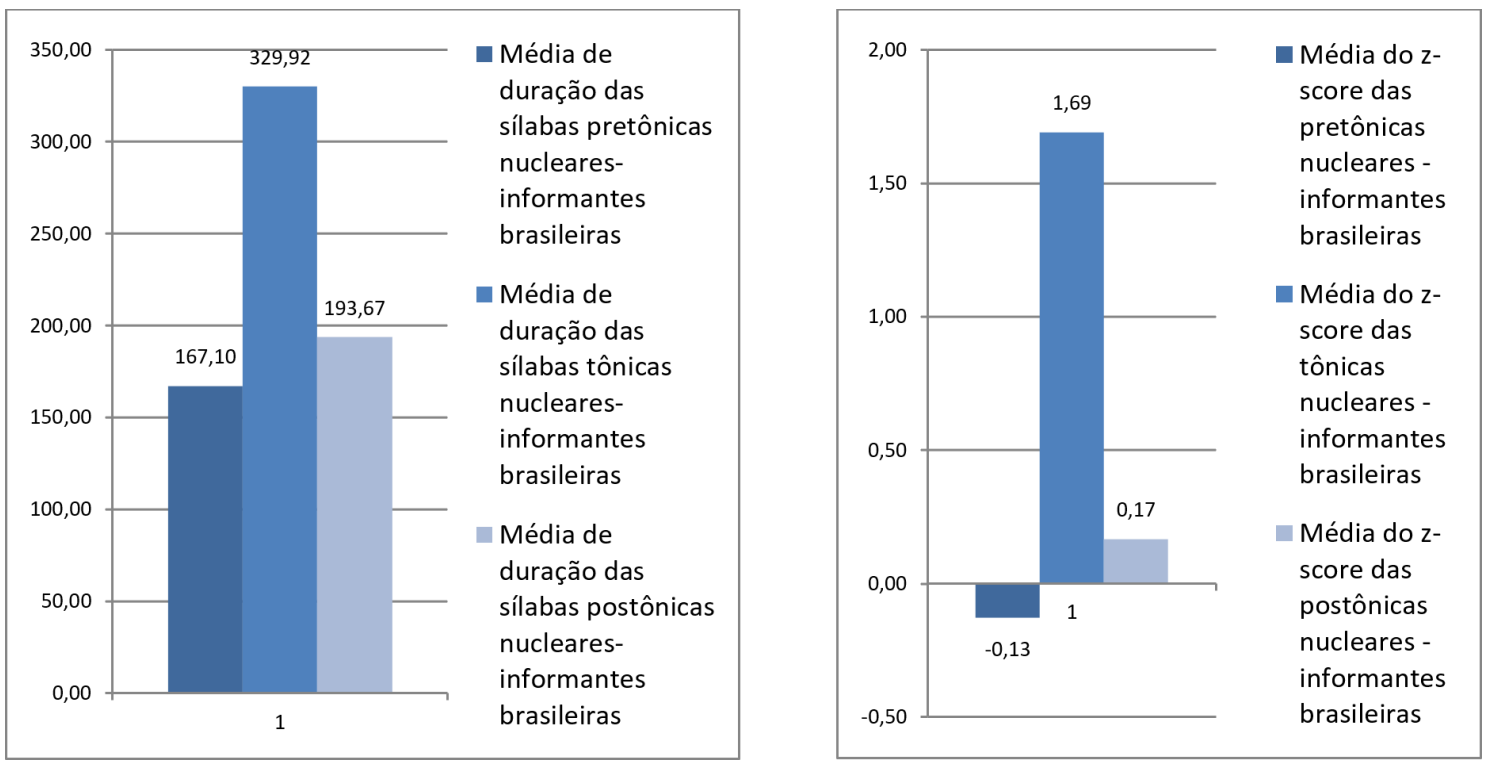

Figura 17: Média de duração das sílabas Figura 18: Média do z-score da região da região nuclear - em perguntas parciais - nuclear em perguntas parciais- informantes informantes brasileiras brasileiras

\subsubsection{Informantes espanholas}

\subsubsection{Frequência fundamental}

Os enunciados do tipo perguntas parciais das informantes espanholas apresentam padrão majoritariamente descendente, iniciando o enunciado com F0 alta e terminando com F0 baixa ( 9 de 12). Entretanto em 2 dos 12 enunciados a curva de F0 sobe na tônica ou na postônica nucleares. No enunciado ¿Por que? dito pela informante $\mathrm{H}$ (Figura 22), composto apenas por região nuclear, observa-se um padrão com curva melódica ascendente. $\mathrm{O}$ padrão ascendente em perguntas pronominais foi considerado por Navarro Tomás (1944) como expressando insegurança ou suavidade, cortesia. 


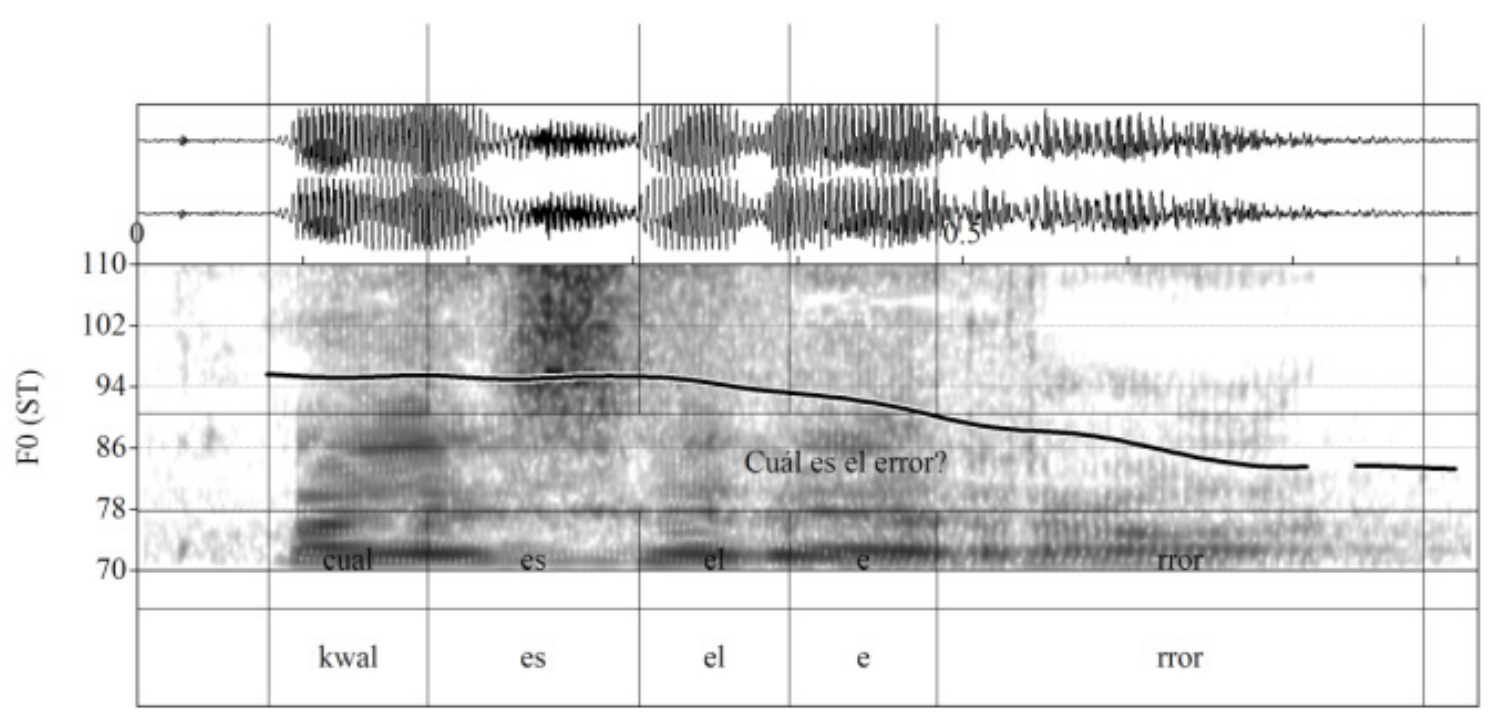

Figura 19: Pergunta parcial ¿Cuál es el error? Com padrão de F0 descendente, informante $\mathrm{Su}$.
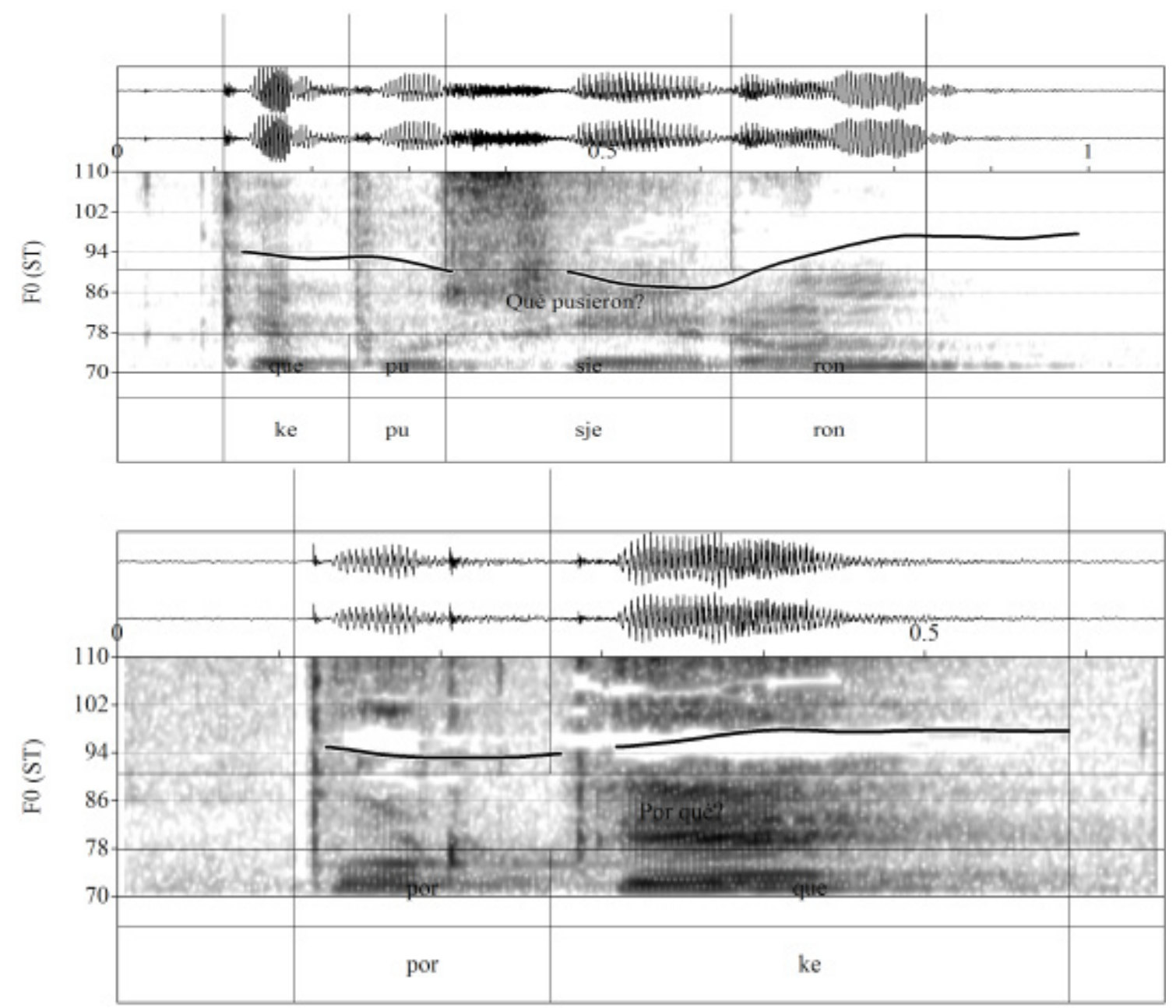

Figura 20: Pergunta parcial ¿Qué pusieron? E ¿Por qué? padrão ascendente na região nuclear, informante $\mathrm{Su}$ no painel superior, $\mathrm{H}$, no inferior. 
Com base na observação dos valores de F0máxima e F0mínima é possível afirmar que as espanholas além de excursionarem por uma faixa de frequência menos extensa, o fazem, em média, em frequências mais baixas do que as das brasileiras nas regiões prenucleares e nucleares dos enunciados do tipo questão parcial.

\subsubsection{Duração}

A duração das sílabas da região prenuclear está representada nasFiguras 23 e 24 . Nesta região a tendência é o encurtamento das sílabas ( $z$-score negativo).
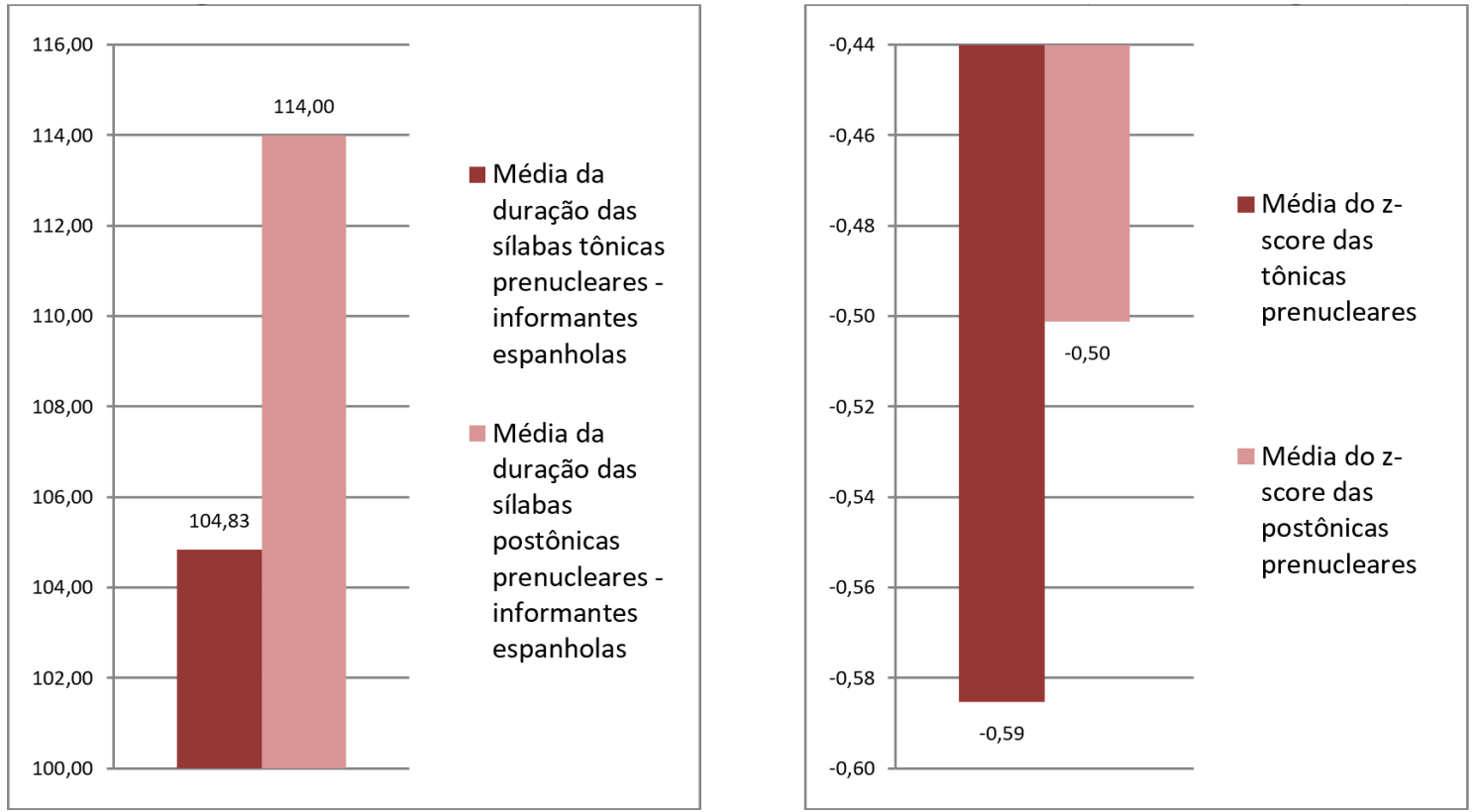

Figura 21: Média da duração das sílabas da Figura 22: Média do $z$-score das sílabas da região prenuclear em perguntas parciais - região prenuclear em perguntas parciaisinformantes espanholas informantes espanholas

Na região nuclear, o que chama atenção é o alongamento das sílabas tônicas e o encurtamento ( $z$-score negativo) das pretônicas e postônicas da região nuclear. 

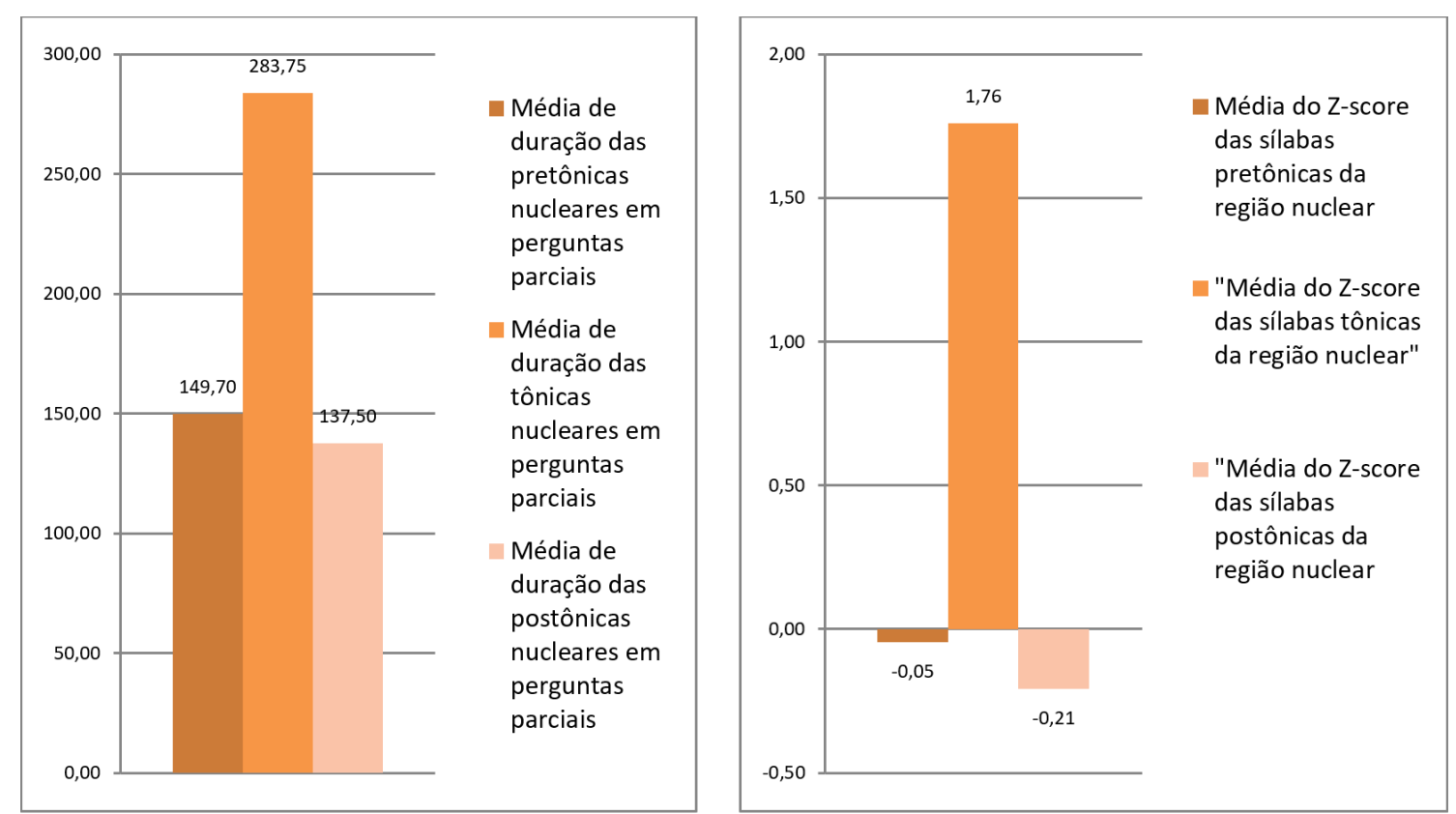

Figura 23: Média da duração das sílabas da Figura 24: Média do $z$-score das sílabas da região nuclear - informantes espanholas região nuclear - informantes espanholas

Contrariando as expectativas, observa-se que as informantes espanholas, assim como as brasileiras, em enunciados do tipo pergunta parcial alongaram mais as sílabas tônicas nucleares.

\subsection{Asserções}

\subsubsection{Informantes brasileiras}

\subsubsection{Frequência fundamental}

O contorno melódico das asserções produzidas pelas brasileiras se caracteriza por uma curva de F0 ascendente na região prenuclear e, seja descendente ( 12 enunciados da informante $\mathrm{C}$ e 4 enunciados da informante $\mathrm{T}$ ); seja ascendente-descendente (4 de 12 dados da informante $\mathrm{T}$ ) ou ainda ascendente ( 4 de 12 dados da informante $\mathrm{T}$ ) na região nuclear. 


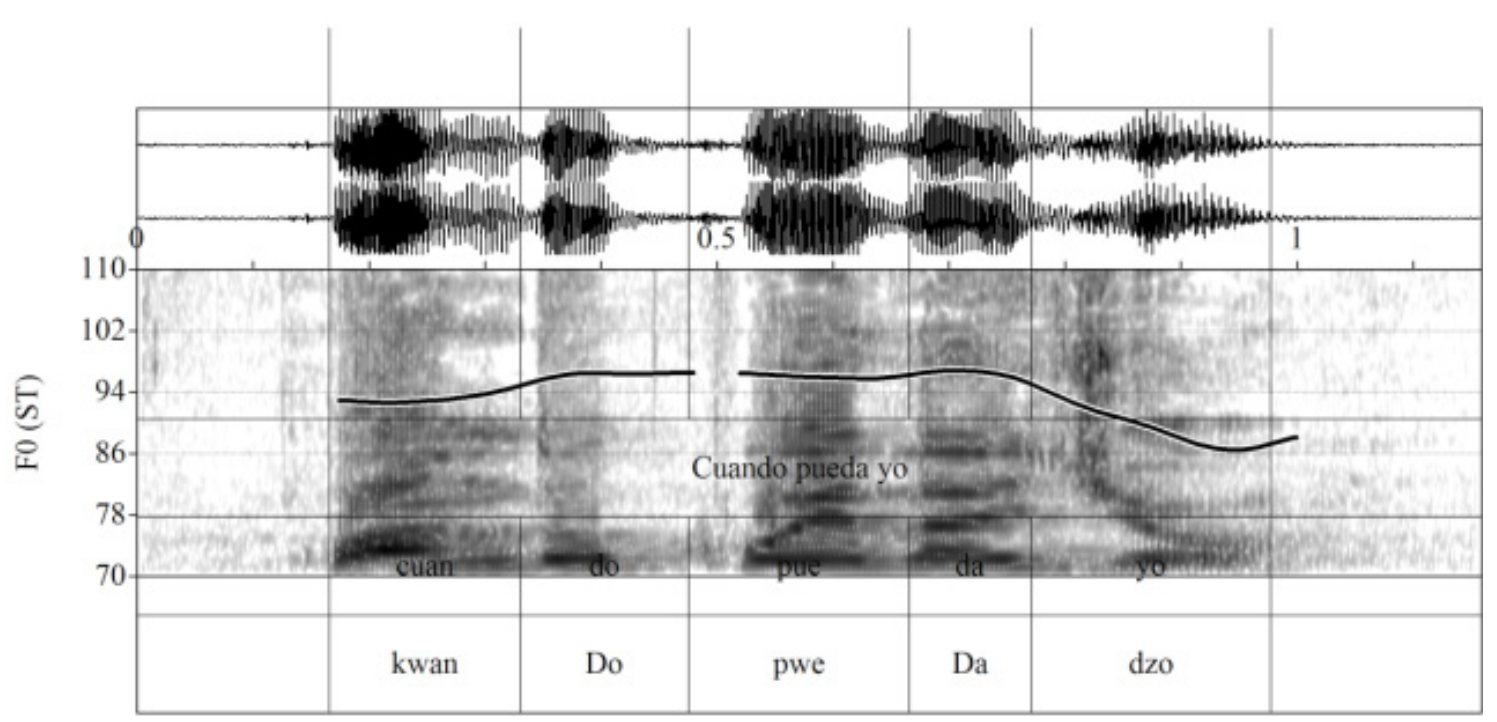

Figura 25:Asserção Cuando pueda yo. com padrão ascendente na região prenuclear e descendente na região nuclear, informante $\mathrm{T}$.

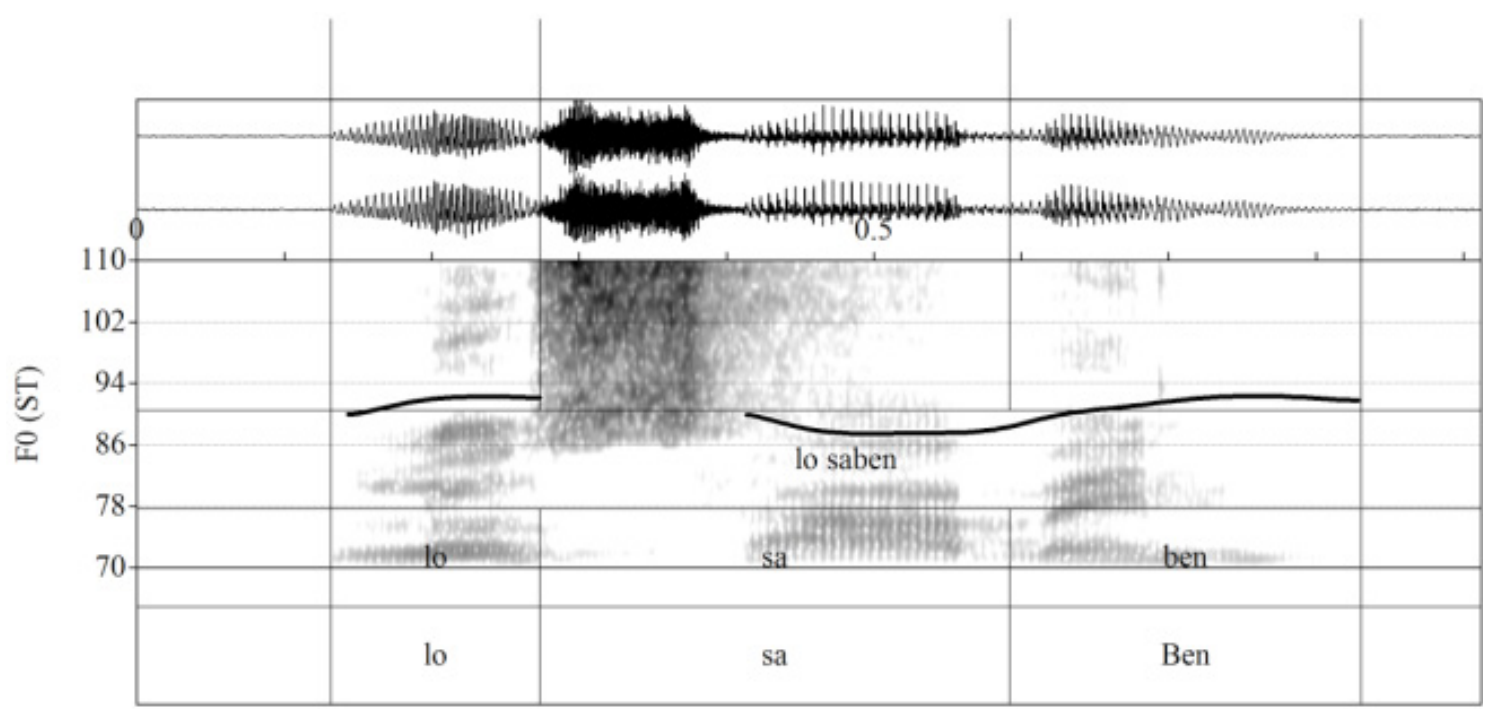

Figura 26: Asserção Lo saben com contorno ascendente na região nuclear, informante T.

\subsubsection{Duração}

Pode-se afirmar que na posição prenuclear, as sílabas tônicas são as mais longas, seguida pelas postônicas e pretônicas respectivamente. Os valores de $z$-score apontam para a tendência de alongamento das sílabas tônicas e encurtamento das pretônicas e postônicas, sendo as últimas as mais breves (menor valor de $z$-score e mais afastado da média, ainda que muito próximo de zero). 

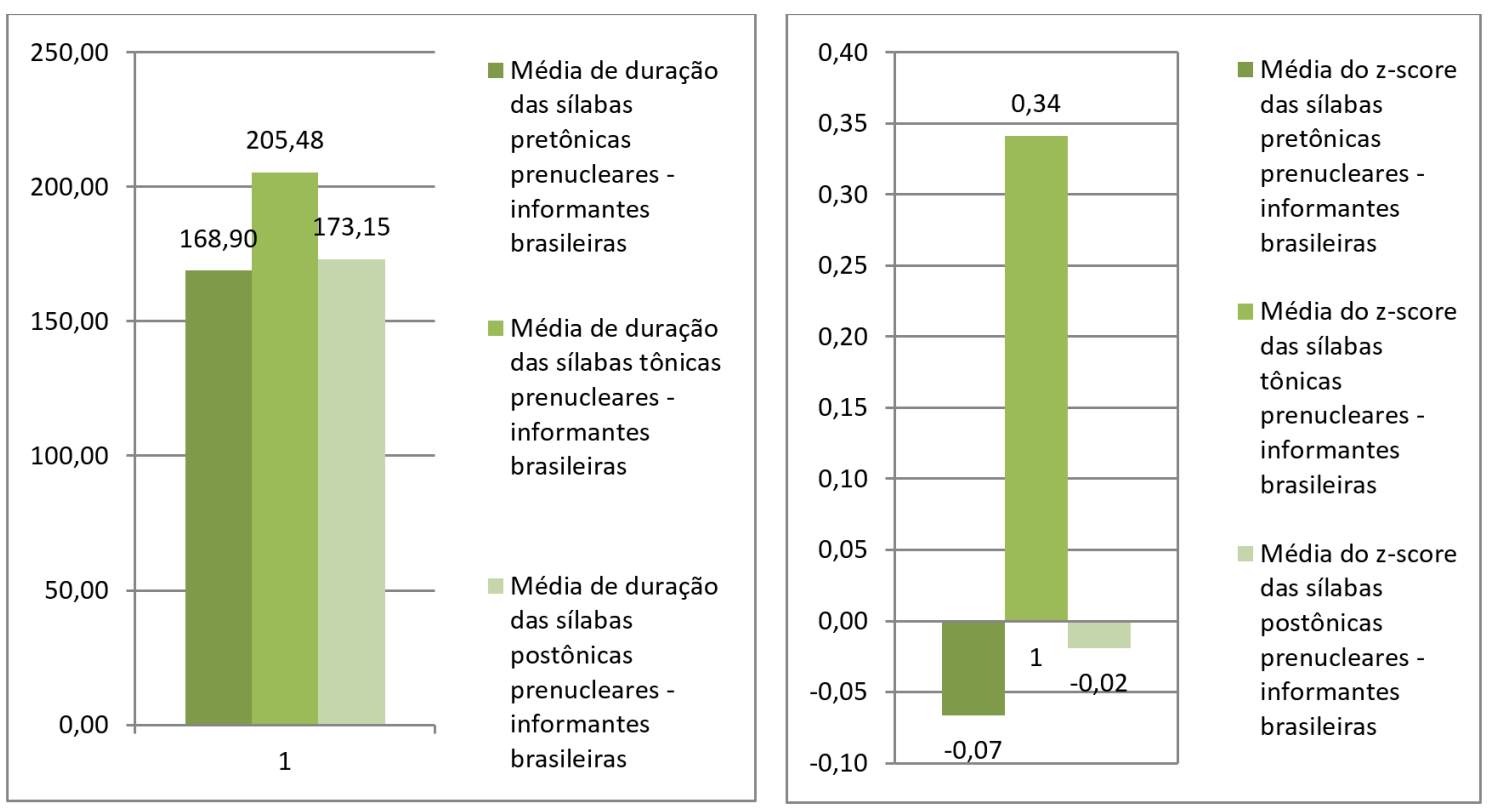

Figura 27: Média de duração das sílabas da Figura 28: Média do $z$-score para as sílabas da região prenuclear - informantes brasileiras região prenuclear - informantes brasileiras

O comportamento das sílabas da região nuclear pode ser visto nas Figuras 31 e 32.
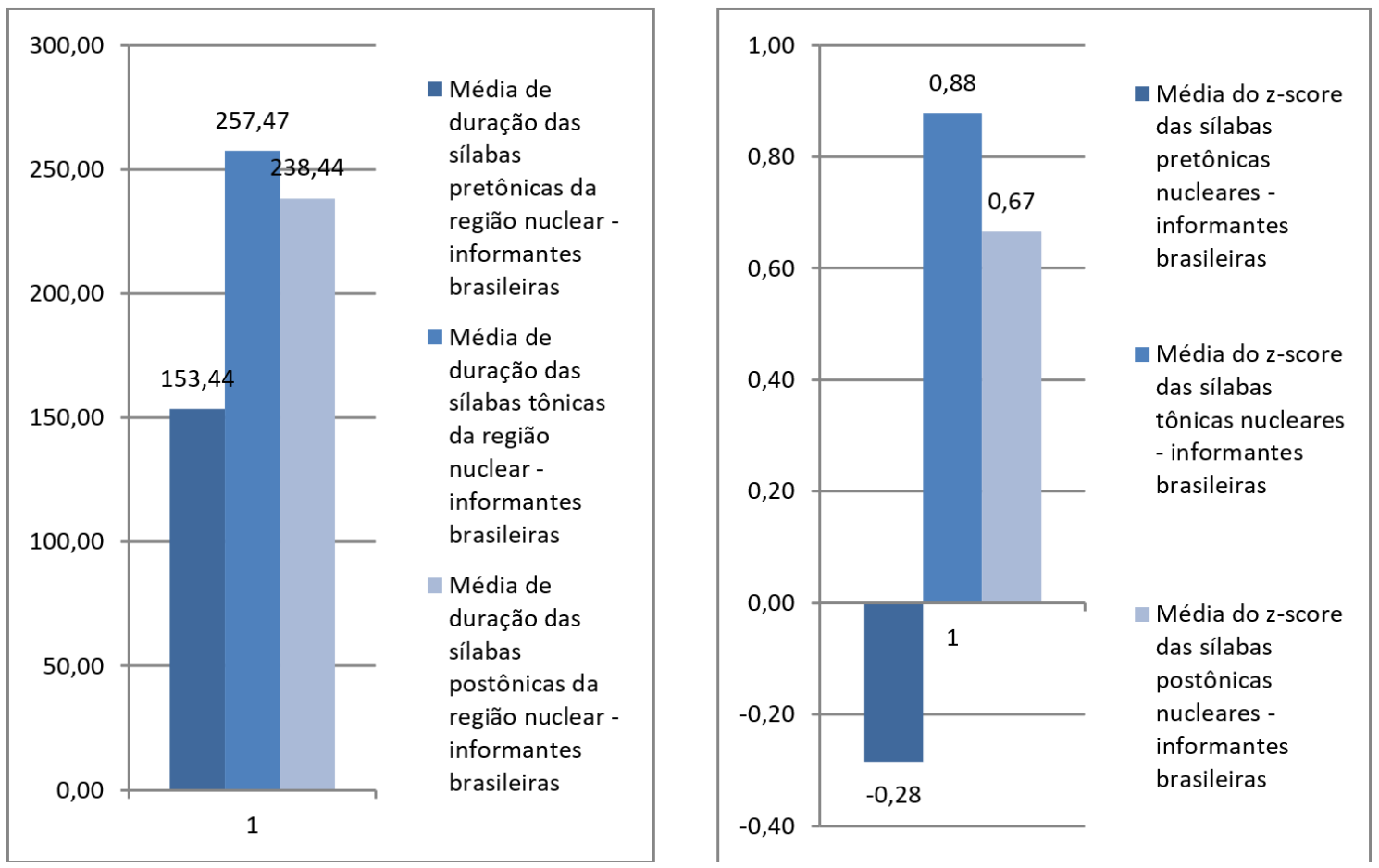

Figura 29: Média de duração das sílabas da Figura 30: Média do $z$-score das sílabas da região nuclear - informantes brasileiras região nuclear - informantes brasileiras 
Conforme se pode observar, as sílabas tônicas são em média as mais longas, seguidas pelas postônicas e pretônicas. Os valores de $z$-score mostram a tendência para alongamento das tônicas e postônicas e encurtamento das pretônicas, sendo que as tônicas são as sílabas que mais sofrem alongamento, como também acontece em português.

\subsubsection{Informantes espanholas}

\subsubsection{Frequência fundamental}

O contorno melódico das asserções das informantes espanholas se caracteriza por padrão ascendente na região prenuclear e principalmente pelo padrão descendente (Figura 33) na região nuclear (6 de 12 dados de Su e 6-de 12 dados de H), podendo, entretanto, tomar uma forma seja plana ( 1 de 12 dados de Su e 4 de 12 dados de H), ascendente-descendente ( 2 dados de 12 de Su); e, ainda, ascendente ( 2 de 12 dados de Su e 1 de 12 dados de $\mathrm{H}$ ). Chama atenção o número de enunciados produzidos com pouca variação de amplitude de F0.

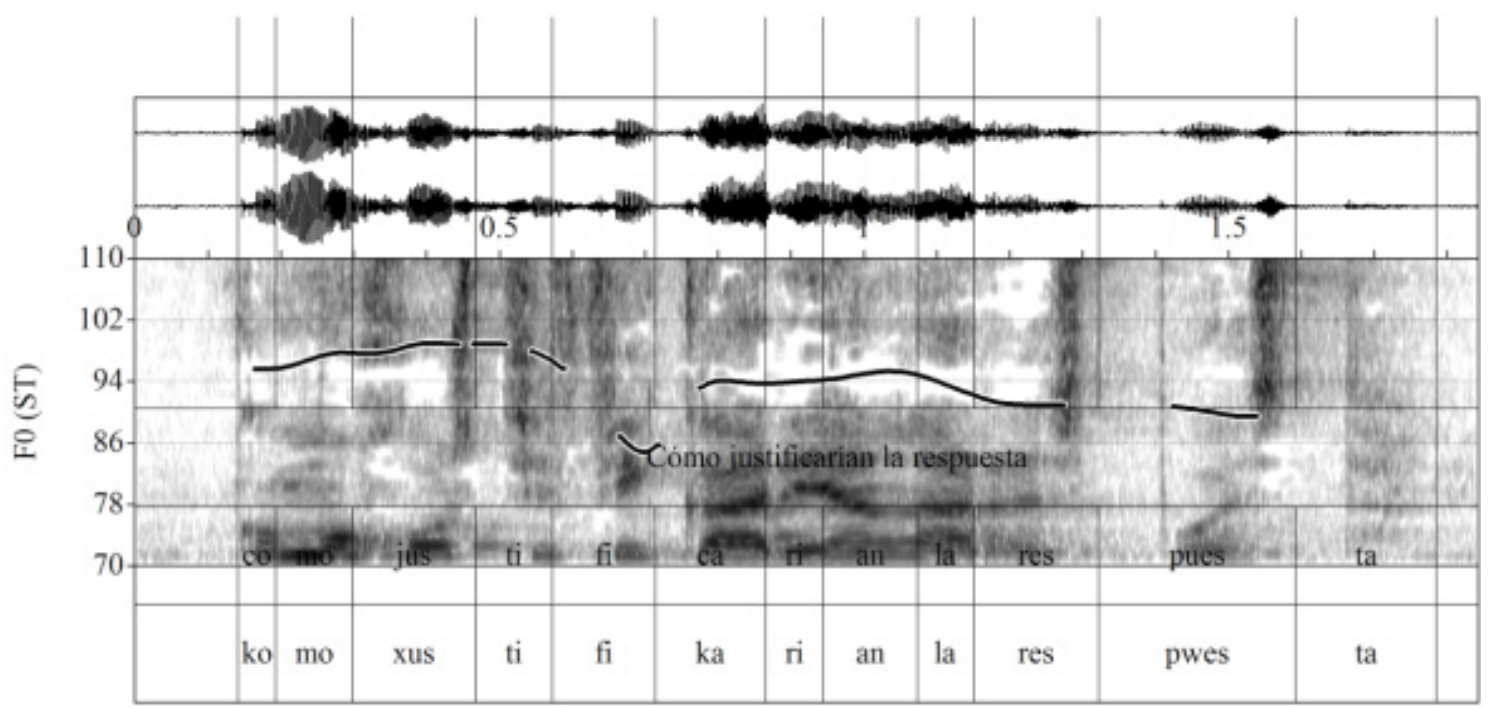

Figura 31: Asserção Como justificarían la respuesta. com padrão ascendente na região prenuclear e principalmente pelo padrão descendente, informante $\mathrm{H}$.

\subsubsection{Duração}

Na região prenuclear (Figuras 34 e 35) as sílabas mais longas são as pretônicas, seguidas das tônicas e postônicas, sendo que os valores de $z$-score indicam que as sílabas pretônicas e tônicas sofrem alongamento (valor de $z$-score positivo, ainda que muito próximo de zero, no caso das tônicas), enquanto que as postônicas tendem a sofrer encurtamento. 

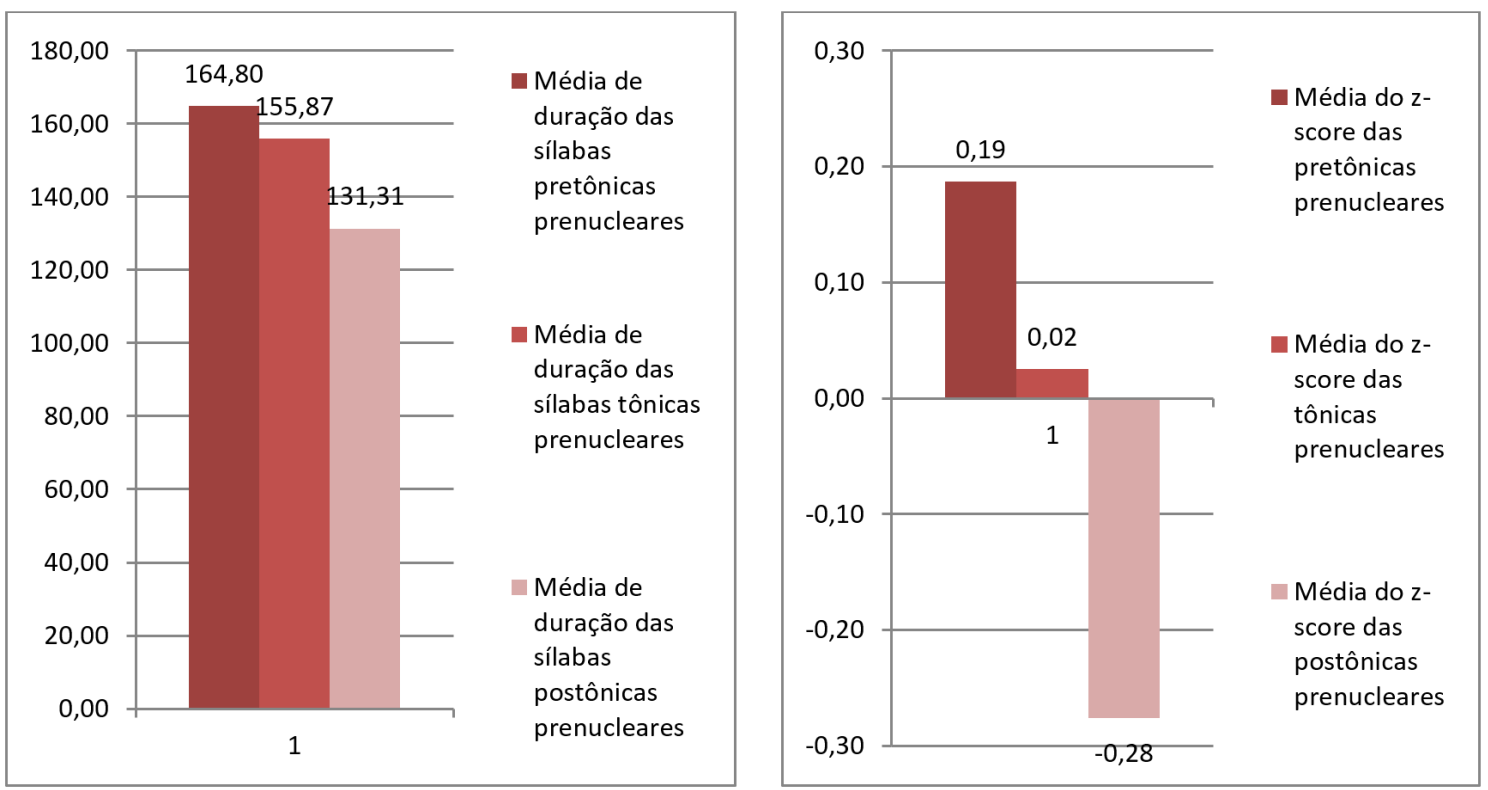

Figura 32: Média da duração das sílabas Figura 33: Média do z-score das sílabas prenucleares em asserções - informantes prenucleares em asserções - informantes espanholas espanholas

As Figuras 36 e 37 mostram os valores médios de duração das sílabas e os valores de $z$-score, respectivamente, para as sílabas da região nuclear dos enunciados assertivos.

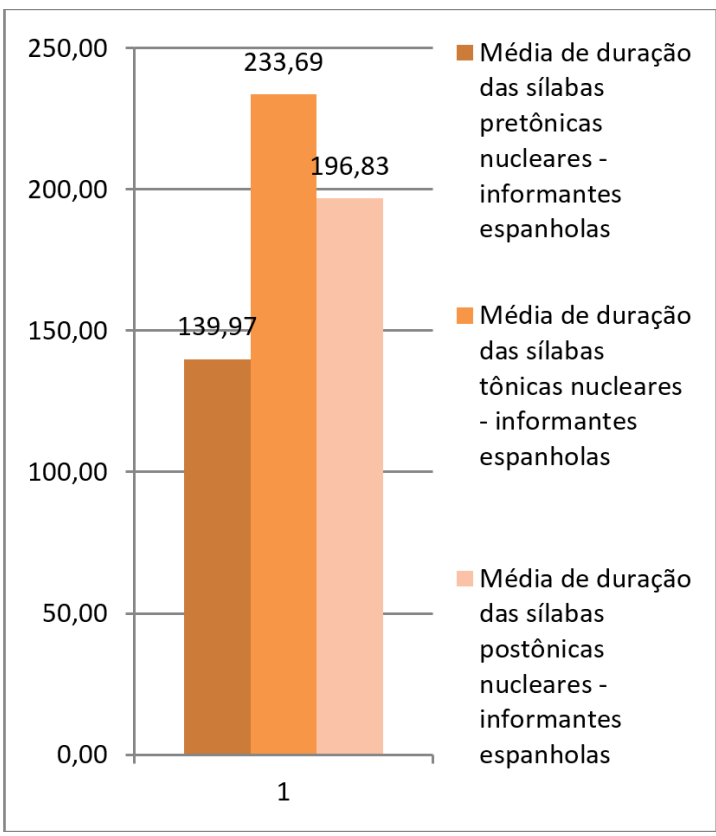

Figura 34: Média de duração das sílabas da região nuclear - informantes espanholas

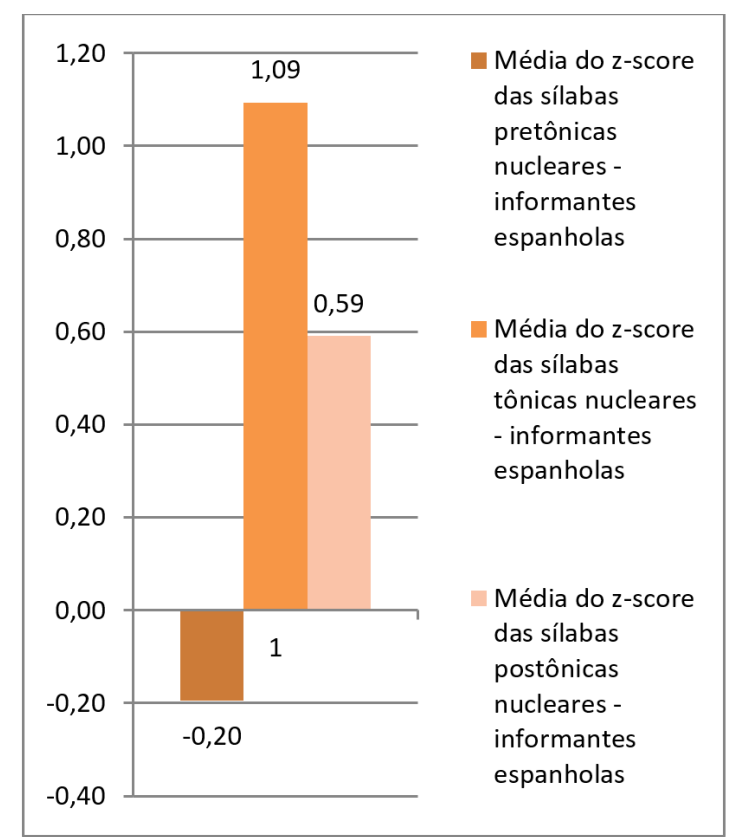

Figura 35: Média do $z$-score das sílabas da região nuclear - informantes espanholas 
Na região nuclear, as sílabas tônicas são as mais longas e seu respectivo valor de $z$-score comprova que as tônicas nucleares tendem a sofrer alongamento. $\mathrm{O}$ mesmo acontece com as postônicas, sofrem aumento em comparação com a média global. Por fim, as pretônicas nucleares, que apresentam valor de $z$-score negativo, indicando que estas sílabas são mais breves que a média global.

\section{CONSIDERAÇÕES FINAIS}

Os resultados mostram que, de maneira geral, (a) as perguntas totais apresentam movimento ascendente na região prenuclear e na região nuclear; (b) nas perguntas parciais, o movimento melódico predominante é descendente; (c) as asserções se caracterizam por contorno prenuclear ascendente com pico geralmente na sílaba tônica ou postônica prenuclear, queda da F0 ao longo do enunciado e acento nuclear num nível médio ou baixo seguido de $\mathrm{F}_{\text {final }}$ baixa.

No que diz respeito ao parâmetro duração, em enunciados do tipo pergunta total e pergunta parcial, as 4 informantes apresentam padrão semelhante: encurtam as sílabas da região prenuclear e a pretônica nuclear, e alongam tônica e postônica nucleares. Nos enunciados assertivos, observa-se que as informantes brasileiras encurtam as pretônicas e postônicas prenucleares e alongam as tônicas. As informantes espanholas, por sua vez, alongam pretônicas e tônicas prenucleares e encurtam as postônicas. Na região nuclear as 4 informantes apresentam padrão similar, com alongamento das tônicas e postônicas.

Como esperado, a hipótese desta pesquisa foi ratificada. O corpus lido, no qual as informantes têm maior controle sobre sua produção, mostrou que tanto as informantes brasileiras como espanholas realizaram predominantemente contorno melódico esperado para o espanhol. Em um corpus espontâneo, provavelmente, devido ao grau de controle ser menor, seria esperado maior influencia da prosódia do PB na produção das informantes.

Novas pesquisas, com um corpus ampliado contemplando a fala espontânea e com outros tipos de frase, são necessárias para dar prosseguimento a descrições como essa.

\section{Referências}

BALLESTEROS PANIZO, M. P. Hacia una teoría compleja de la entonación y análisis de la melodía del habla de Navarra. RILCE, p. 44-72, 2014.

BARBOSA, P. A. Conhecendo melhor a prosódia: aspectos teóricos e metodológicos daquilo que molda nossa enunciação. Rev. Est. Ling., Belo Horizonte, p. 11-27, 2012.

BARBOSA, P.; CAMARGO, Z. A.; MADUREIRA, S. Scripts for the Acoustic Analysis 
of Speech Data. In: MADUREIRA, S. na declamação / Sonorities [eletronic device]: speech, singing and reciting expressivity. São Paulo: Pontifícia Universidade Católica de São Paulo, 2016. p. 164-174.

BOERSMA, P.; WEENINK, D. Praat: doing phonetics by computer (version 5.1.07), 5 dez. 2009. Disponivel em: http://www.praat.org/.

CANTERO, F. J. Teoría y análisis de la entonación. Barcelona: Ediciones de la Universitat de Barcelona, 2002.

CARDOSO, S. et al. Atlas Linguístico do Brasil - cartas linguísticas 1 - vol. 2. Londrina: Editora da Universidade Estadual de Londrina, 2015.

CASTELO, J. A entoação dos enunciados declarativos e interrogativos no Português do Brasil: uma análise fonológica em variedades ao longo da Costa Atlântica.(tese de doutorado). Lisboa: Universidade de Lisboa, 2016.

CUNHA, C. D. S. Entoação regional no português do Brasil.(tese de doutorado). Rio de Janeiro: Programa de Pós-graduação em Letras Vernáculas da UFRJ, 2000.

DIAS, E. C. O. Declarativas e interrogativas totais no espanhol 11 e 12 falado em bogotá: uma contribuição para estudos prosódicos (tese de doutorado). Florianópolis: Programa de Pós Graduação em Linguística da Universidade Federal de Santa Catarina, 2015.

ESTEBAS VILAPLANA, E.; PRIETO, P. La notación prosódica del español: una revisión del Sp_TOBI. Estudios de Fonética Experimental XVIII, p. 263-283, 2009.

ESTEBAS-VILAPLANA, E.; PRIETO, P. Castilian Spanish Intonation. 4th Sp_ToBI workshop: Transcription of Intonation of the Spanish Language. Las Palmas de Gran Canaria: [s.n.]. 2009. p. 17-48.

FERREIRA DE SÁ, P. C. Análise prosódica de enunciados assertivos e interrogativos totais no espanhol de montevidéu (tese de doutorado). Rio de Janeiro: Faculdade de Letras da UFRJ, 2013.

FROTA, S. Prosody and Focus in European Portuguese: phonological phrasing and intonation. Nova Iorque: Routledge, 2013.

FROTA, S. et al. Intonational variation in Portuguese: European and Brazilian varieties. In: FROTA, S.; PRIETO, P. Intonation in Romance. Oxford: Oxford University Press, 2015. p. 235-283.

GOMES DA SILVA, C. Análise entonacional e pragmática de conversas telefônicas coloquiais: os enunciados interrogativos totais nas variedades de Buenos Aires e Santiago do Chile (dissertação de mestrado). Rio de janeiro: Programa de Pós-Graduação em Letras Neolatinas da Universidade Federal do Rio de Janeiro, 2014.

HIDALGO NAVARRO, A. Aspectos de la entonación española: viejos y nuevos enfoques. Madrid: Arco Libros, 2006. 
HIRST, D.; DI CRISTO, A. A survey of intonation systems. In: HIRST, D.; DI CRISTO, A. Intonation systems: A survey of twentylanguages. Cambridge: Cambridge University Press, 1998. p. 78-96.

LIPSKI, J. M. Geografical and socila varieties of Spanish: an overview. In: HUALDE, J. I.; OLARREA, A.; O'ROURKE, E. The handbook of hispanic linguistics. Oxford: Wiley Blackwell, 2014. p. 1-26.

MIRA MATEUS, M. H. Dialectos e variedades do português. In: MIRA MATEUS, M. H., et al. Gramática da Língua Portuguesa. Lisboa: Editorial Caminho, 2003. p. 39-54.

MORAES, J. A. de. Intonation in Brazilian Portuguese. In: HIRST, Daniel; DI CRISTO, Albert. (Org.). Intonation Systems: a Survey of Twenty Languages. Cambridge: Cambridge University Press, 1998. p. 179-194.

MORAES, J. A. Melodic contours of yes/no questions in Brazilian Portuguese. In: BOTINIS, A. Proceedings of ISCA totorial and Research Workshop on Experimental Linguistics. Athens: University of Athens, Greece, 2006. p. 117-120.

MORAES, J. A. The pitch accents in Brazilian Portuguese. Speech Prosody 4, p. 389397, 2008.

MORAES, J. A.; RILLIARD ,. Illocution, Attitudes and Prosody. In: RASO, T.; MELLO, H. Spoken corpora and linguistic studies. Amsterdam: John Benjamins, 2014. p. 233270.

MORENO FERNÁNDEZ, F. Las variedades de la lengua española y su enseñanza. Madrid: Editorial Arco/Libros, 2010.

NAVARRO TOMÁS, T. Manual de entonación española. New York: Hispanic Institute in the United States, 1944.

OLIVEIRA, A. F. D. Caracterización de la entonación del español hablado por brasileños (tese de doutorado). Barcelona: Facultad de Formación del ProfesoradoUniversitat de Barcelona, 2013.

ORTEGA-LLEBARIA, M.; PRIETO, P. Disentangling stress from accent in Spanish: Production patterns of the stress contrast in deaccented syllables. In: PRIETO, P.; MASCARÓ, J.; JOSEP SOLÉ, M. Segmental and prosodic issues in Romance phonology. Amsterdam: John Benjamins, 2007. p. 155-175.

PINTO, M. D. S. Transferências prosódicas do português do brasil//m na aprendizagem do espanhol/le: enunciados assertivos e interrogativos totais (tese de doutorado). Rio de Janeiro: Faculdade de Letras da UFRJ, 2009.

PRIETO, P.; ROSEANO, P. Atlas interactivo de la entonación del español, 20092013. Disponivel em: http://prosodia.upf.edu/atlasentonacion/index.html. Acesso em: 23 setembro 2016. 
QUILIS, A. Tratado de fonologia y fonética españolas. Madrid: Gredos, 1993.

RAO, R. Final Lengthening and Pause Duration in Three Dialects of Spanish. In: ORTEGA-LLEBARIA, Selected Proceedings of the 4th Conference on Laboratory Approaches to Spanish Phonology. Somerville, MA: Cascadilla Proceedings Project, 2010. p. 69-82.

SANTOS, C. F. D. Análise interlinguística da entoação e da duração em variedades de contato e de não contato do espanhol do uruguai e do português do sul do brasil (tese de doutorado). Rio de Janeiro: Faculdade de Letras da UFRJ, 2012.

SILVA, C. C. análise fonético-experimental da entoação de declarativas e interrogativas em espanhol/LE. Campinas: [s.n.], 2016.

SILVESTRE, A.A entoação regional dos enunciados assertivos nos falares das capitais brasileiras (dissertação de mestrado). Rio de Janeiro: Programa de PósGraduação em Letras Vernáculas da Universidade Federal do Rio de Janeiro, 2012.

SILVESTRE, A.; CUNHA, C. Pelos cantos do brasil: a variação entocional da asserção neutra em natal, rio de janeiro e porto alegre. Letrônica, p. 179-195, 2013.

SOSA, J. M. La entonación del español: su estructura fónica, variabilidad y dialectología. Madrid: Cátedra, 1999.

SOSA, J. M. Wh-questions in Spanish:Meanings and Configuration Variability. Catalan Journal of Linguistics 2, 2003. 229-247.

TRUCKENBRODT, H.; SANDALO, F.; ABAURRE, M. Elements of Brazilian Portuguese Intonation. Journal of Portuguese Linguistics, v. 8, p. 75-114, 2009.

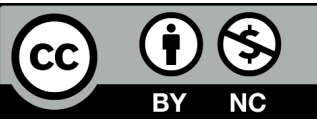

Data de submissão: 14/03/2018

Data de aceite: $14 / 07 / 2019$ 